The INL is a

U.S. Department of Energy

National Laboratory

operated by

Battelle Energy Alliance

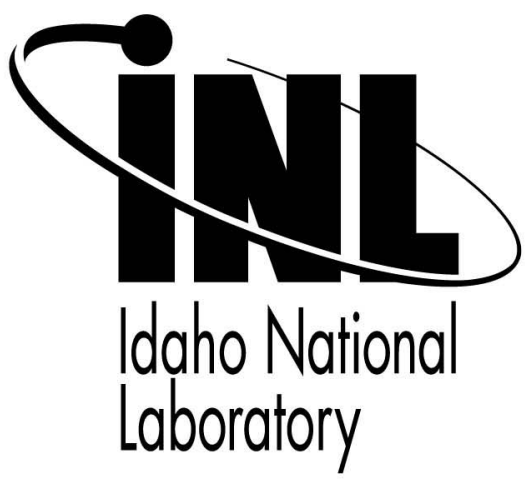

INL/CON-06-01254

PREPRINT

\title{
Observations on \\ Characterization of \\ Defects in Coiled Tubing \\ From Magnetic-Flux- Leakage Data
}

\section{SPE/ICoTA Coiled Tubing and Well Intervention Conference and Exhibition}

\author{
Timothy R. McJunkin \\ Karen S. Miller \\ Charles R. Tolle
}

April 2006

This is a preprint of a paper intended for publication in a journal or proceedings. Since changes may be made before publication, this preprint should not be cited or reproduced without permission of the author. This document was prepared as an account of work sponsored by an agency of the United States Government. Neither the United States Government nor any agency thereof, or any of their employees, makes any warranty, expressed or implied, or assumes any legal liability or responsibility for any third party's use, or the results of such use, of any information, apparatus, product or process disclosed in this report, or represents that its use by such third party would not infringe privately owned rights. The views expressed in this paper are not necessarily those of the United States Government or the sponsoring agency. 


\section{Observations on Characterization of Defects in Coiled Tubing From Magnetic-Flux- Leakage Data \\ Timothy R. McJunkin, Idaho National Laboratory; Karen S. Miller, Idaho National Laboratory; and Charles R. Tolle, Idaho \\ National Laboratory}

\begin{abstract}
This paper presents observations on the sizing of automatically detected artificial flaws in coiled tubing samples using magnetic-flux-leakage data. Sixty-six artificial flaws of various shapes and types, ranging from $0.30 \mathrm{~mm}$ deep pits to slots with length of $9.5 \mathrm{~mm}$, in $44.45 \mathrm{~mm}$ outer diameter pipe were analyzed. The detection algorithm and the information automatically extracted from the data are described. Observations on the capabilities and limitations for determining the size and shape of the flaws are discussed.
\end{abstract}

Defects in coiled tubing (CT) degrade the longevity of the CT and, therefore, need to be detected to prevent costly failures in the field. One commonly used method for nondestructively examining CT is magnetic flux leakage (MFL), where a magnetic field is generated with a coil or permanent magnets and Hall-effect sensors located around the CT measure the variation in the field near the surface of the CT. The size, shape, and location of the flaws are an important attribute in determining the point of failure. Characterizing flaws is important to closing the loop on failure prediction models ${ }^{1}$. The size and shape of flaw determines the severity index, developed at the University of Tulsa and is directly related to the expected life of a CT string.

This paper presents the algorithm for automatically extracting information from the MFL signals. An effective method for detecting the signature of flaws in the MFL signal has been developed $^{2}$ and is summarized. In support of failure prediction models, this paper presents the currently observed capabilities of determining the type, size, and severity of flaws present in coiled tubing from MFL. The size and shape of the flaw influences the amplitude and duration of the MFL signals. The extent to which the flaws can and cannot be characterized is

\section{Introduction}

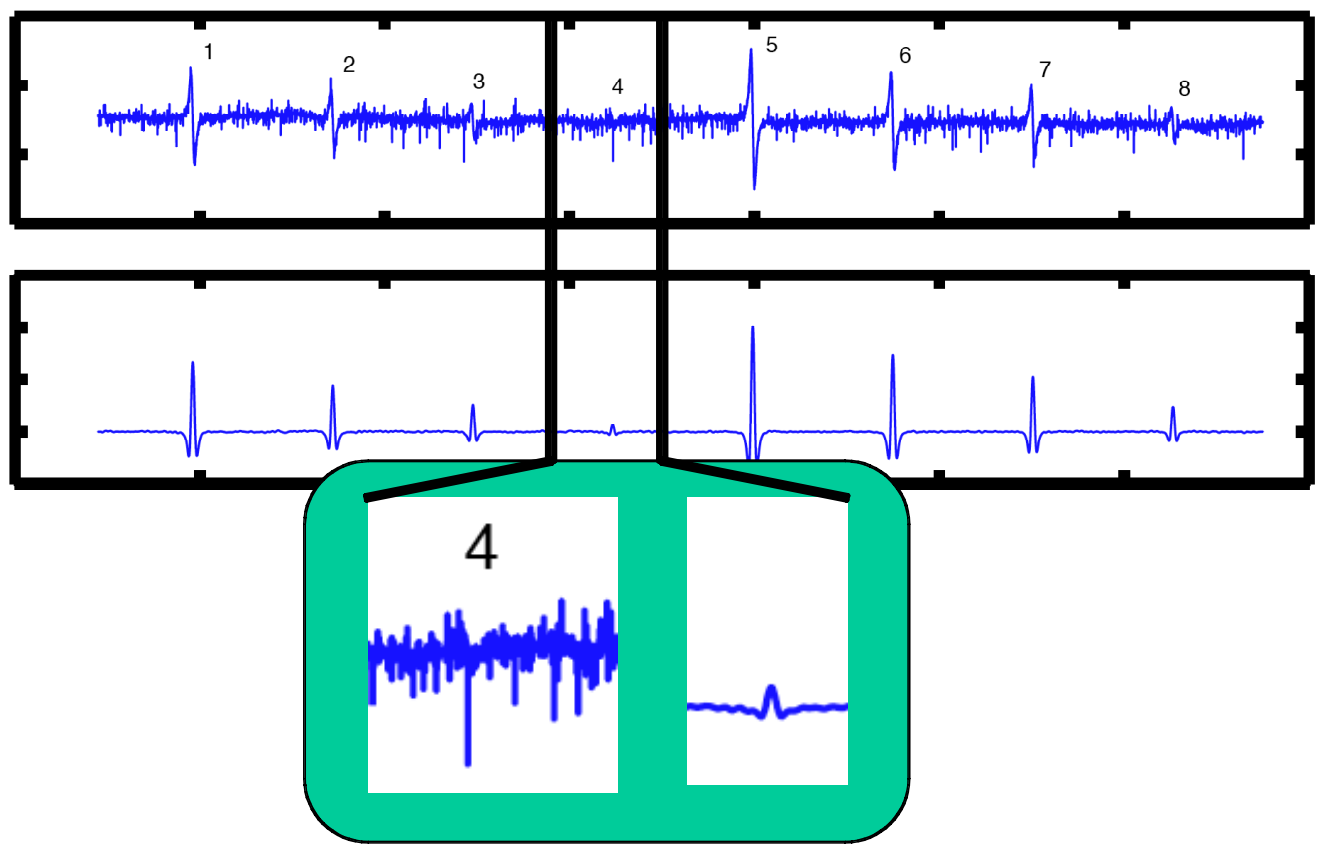

Figure 1. Example of the capabilities of the designed matched filter at maximizing the signal to noise ratio from the radial component of the MFL sensor. In this example the Butterworth pre-filter stage has been omitted. The top signal shows an unfiltered radial component signal of a CT sample with artificial flaws of various sizes. The middle row shows the response of the matched filter to the signal. The bottom signals show an enlargement of the signal (left) and filter response (right) to the smallest flaw. 

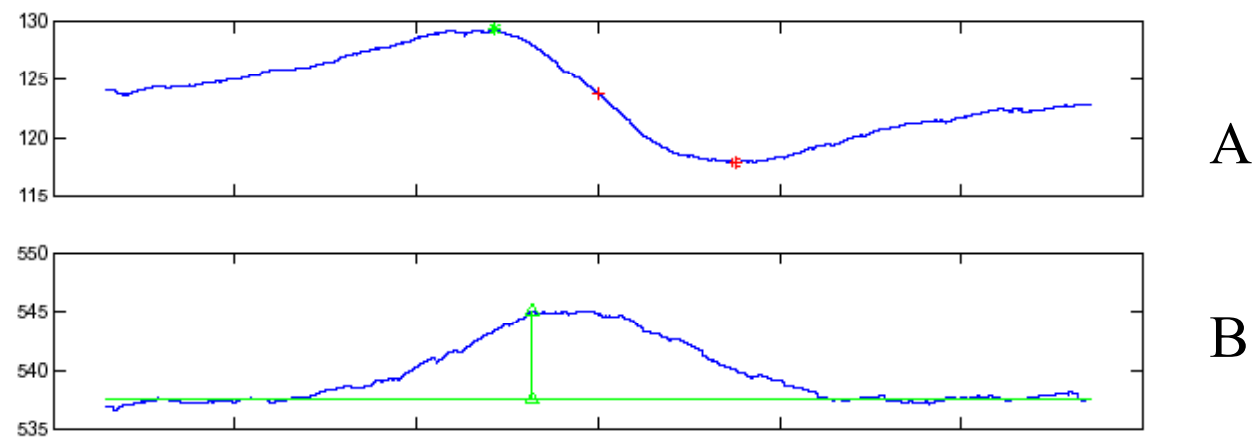

B
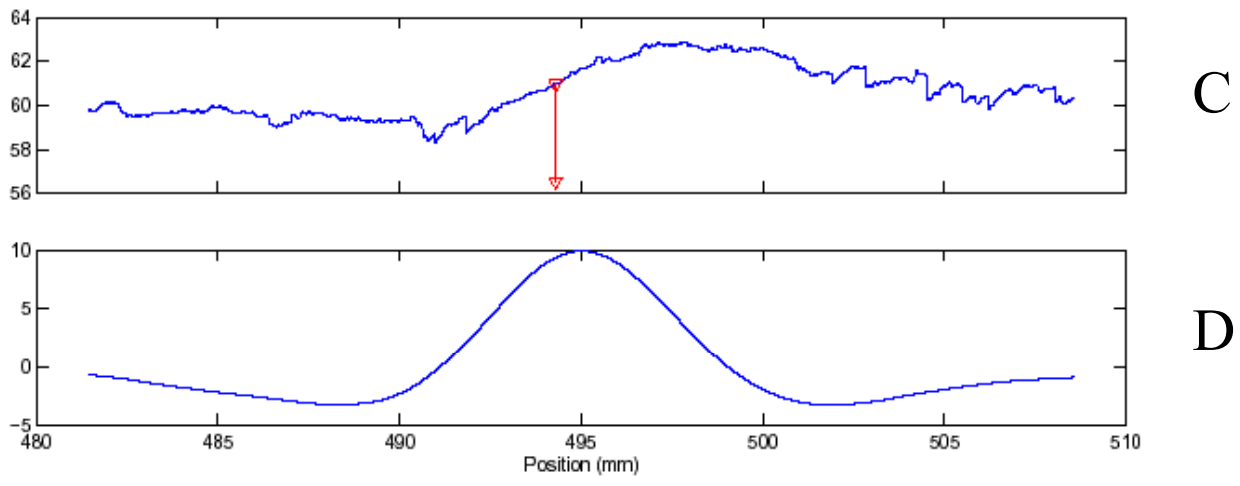

Figure 2. The three orthogonal components of the MFL field at a defect and the parameters that are collected for each component are shown. A) The radial component with the position of the center of the signal and the maximum and minimum point on the signal. B) The axial or longitudinal component shown with the base line (horizontal line) and amplitude above the baseline. C) The circumferential signal with an arrow indicating the amplitude and direction of the indication. D) The output of the matched filter applied to the radial component.

discussed. Presentations of the primary issue in discriminating crack type flaws from other less serious flaws conclude with the possible paths forward for resolving the issue.

\section{Description and Application of Equipment and Processes}

To collect MFL data, a laboratory scale experimental CT MFL sensor head has been constructed. The coil used to create the field in and around the CT is an $89 \mathrm{~mm}$ long solenoid with a $102 \mathrm{~mm}$ inner diameter. There are 1400 revolutions (turns) of 18 gauge copper wire wound evenly along the length of the coil. Data presented in this paper was acquired using $5 \mathrm{~A}$ direct current in the coil. This level is adequate to saturate the pipe and allow detection of flaws on the inner surface of the CT. Plastic frames, "shoes", were populated with 3 ratiometric linear Hall-effect sensors oriented in each of the orthogonal components for cylindrical coordinates: radial, longitudinal (axial), and circumferential. Five shoes where distributed circumferentially around approximately one fourth the circumference of the CT samples. Artificial defects were run by the sensors, nominally centered on the middle of the 5 shoes. For experimental convenience, the magnet and sensors are moved with a linear slide driven by a stepper motor.

Data from the Hall effect sensors was acquired with a digital acquisition card sampling each single at a rate of 2000 samples/s. A first-order low pass Butterworth filter with a cutoff frequency of $100 \mathrm{~Hz}$ was applied as a digital filter in software in all but one example in this paper. The time series signal was converted to a distance versus amplitude by adjusting for scan velocity and sample rate.
The radial component signal was utilized for flaw detection. Signal processing was applied to allow for effective detection of flaws with few false positives. A matched filter designed for the signature of small defects was correlated with the MFL signal. A matched filter produces a maximum ratio of response to the desired waveform to that of noise. For the signal produced by a small flaw, the optimal filter was determined to be the derivative of a Gaussian function with the peak-to-peak duration matching that of a minimum flaw that is to be detected ${ }^{2}$. Although the filter is not optimized for larger flaws the shape of their signal is close enough and amplitude sufficient to allow detection. The response produces a positive pulse in the output of the filter when a flaw signal overlaps the signal. A threshold value was heuristically determined such that it was above the noise level response but below the response to a small flaw. To further reduce false detections a minimum width of the response signal was also implemented. The width of the response was measured from the first zero crossing on each side of the peak. A minimum width value was chosen to be slightly shorter than the autocorrelation of the matched filter. The values used for the filter and threshold used for this paper are:

- $l_{d}$ - peak-to-peak duration of $h(n)-3.4 \mathrm{~mm}$

- $T_{A}$ - amplitude threshold -2.5

- $T_{W}-$ minimum response width $-4.5 \mathrm{~mm}$

The function implementing the filter is 

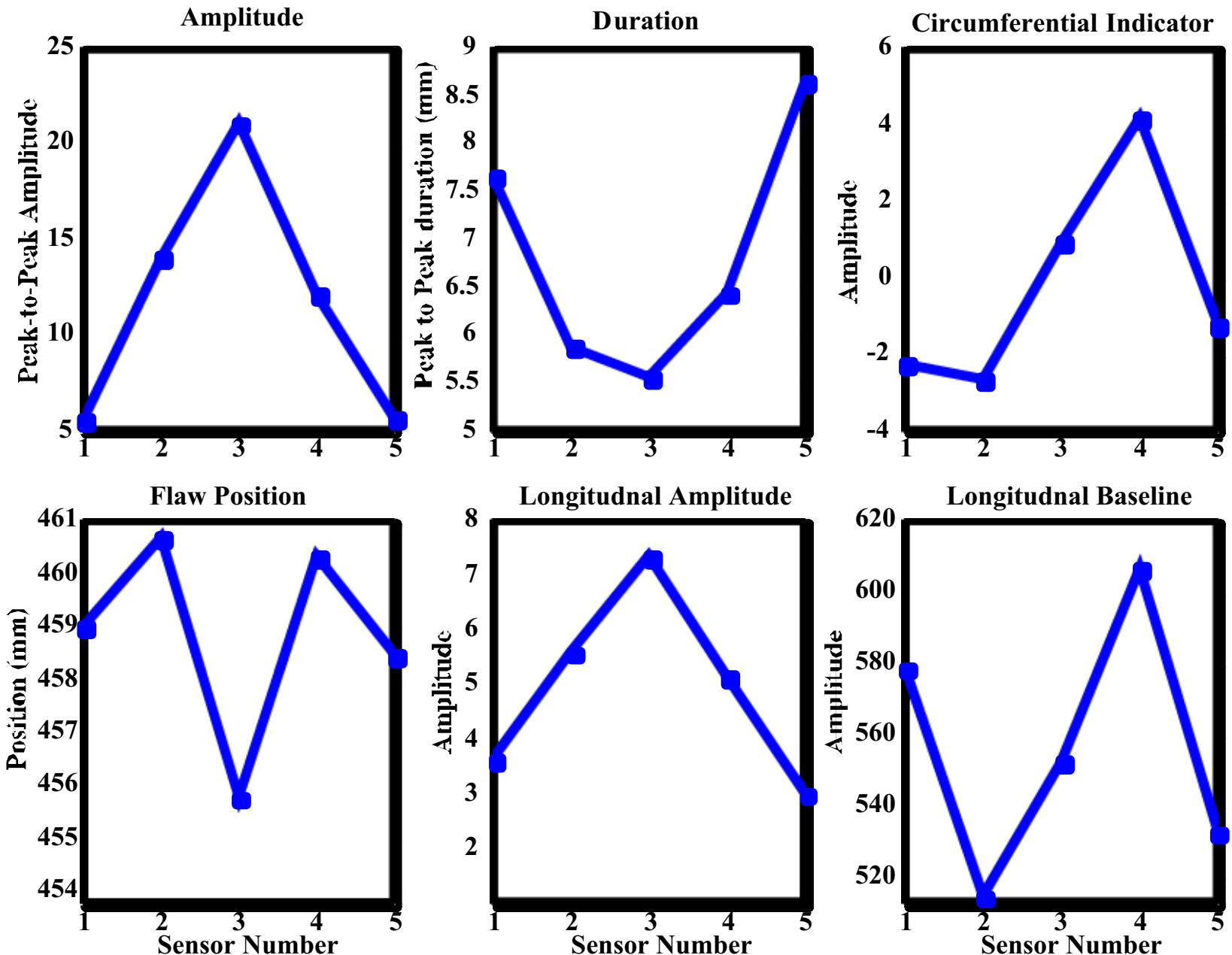

Figure 3. Combined information from the five sets of sensors for one defect. Each sensor number represents one set of sensors at a circumferential position. The flaw was nominally aligned on sensor number 3 .

$$
\begin{aligned}
h(n) & =-2 \kappa n e^{-(\kappa n)^{2}} \\
& \kappa=\frac{v T \sqrt{2}}{l_{d}} \\
n & \text { is the sample number } \\
T & \text { is the sample period }(\mathrm{s}) \\
v & \text { is the translation velocity }(\mathrm{mm} / \mathrm{s}) \\
l_{d} & \text { is the peak-to-peak duration }(\mathrm{mm}) .
\end{aligned}
$$

The output response at a location in the sampled signal is

$$
\nu(n)=\sum_{i=-L}^{L} s(i+n) h(i)
$$

with $L$ set to a reasonable length for the filter. We chose a number of samples equivalent to two times $l_{d}$, or $L$ is equivalent to the nearest integer to $l_{d}$ divided by the product of the velocity and sample period.

The detection algorithm was implemented in software that post-processes data acquired with the experimental sensor head. Signal data from the radial component for each sensor position was processed for responses that exceed the defined thresholds. Figure shows the capability of the matched filter in discriminating a flaw from the noise even when the signal from the flaw is buried in the noise (flaw 4). This example uses data were the Butterworth filter was not performed on the data before applying the matched filter, to emphasize the matched filters capability to reject noise.

At each point that detection occurs, additional information is extracted from the signals of all three orthogonal components. The information abstracted from the signals is shown in Figure 2. The first is the axial (longitudinal) position, $p$, of the peak of the response. From the radial signal the local minimum and maximum around the peak of the filter response location is determined by search backward and forward in the data as much as $41_{d}$. From the minimum and maximum location, the radial signal amplitude, $\mathrm{a}_{r}$, is recorded as the absolute value of the difference in the amplitude of the to local extremes. The absolute value of the difference in axial position of these points is recorded as the duration, $d$, of the signal. From the longitudinal component signal, the amplitude of the baseline, $a_{b}$, and the peak amplitude minus the baseline, $a_{l}$, are found. The circumferential component signal has a shape similar to that of the radial component; however, it 


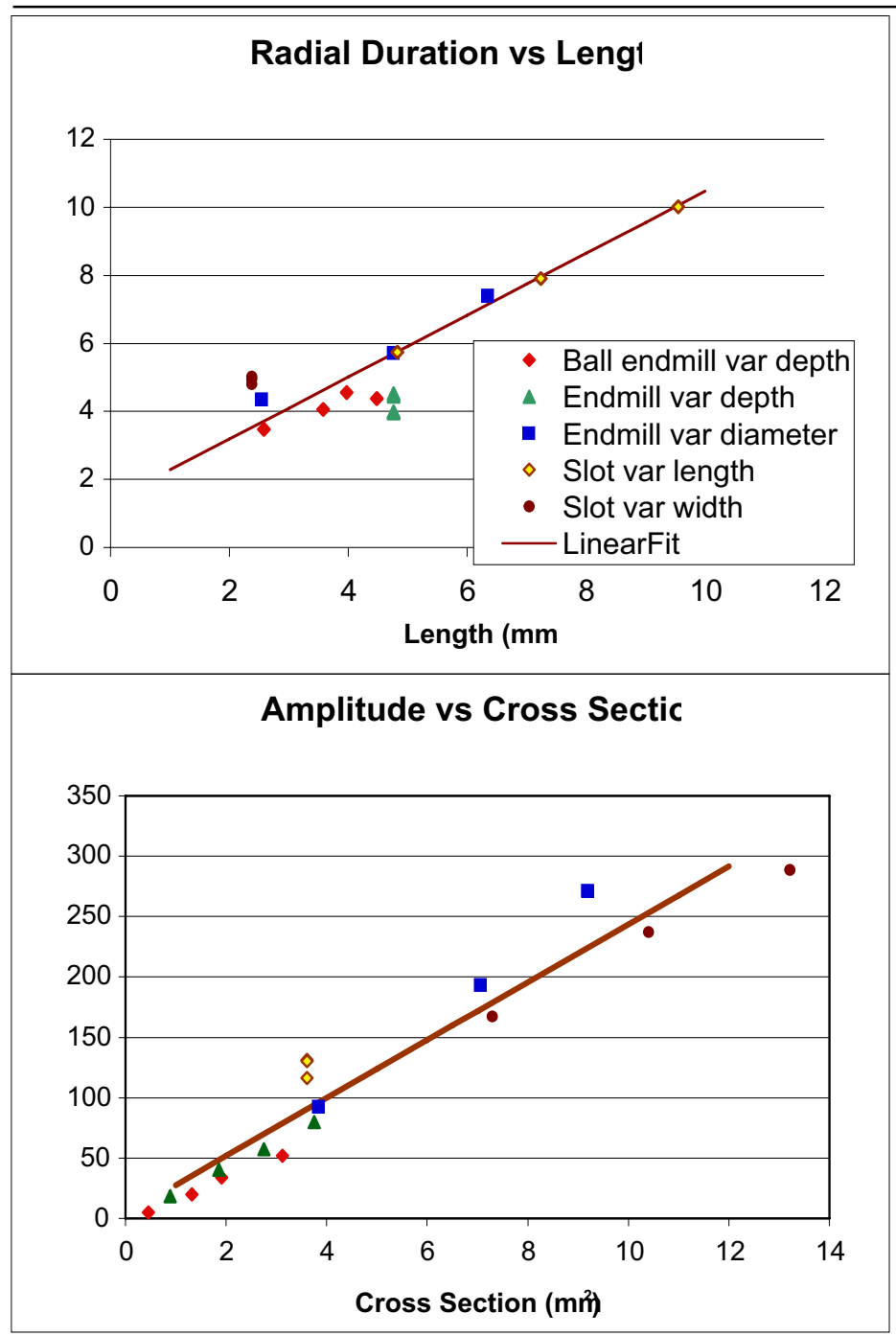

Figure 4. Comparison of duration of the radial signal to the length of flaws and the amplitude to the cross-sectional area. Least squares linear fit for each is shown. Flaws are all external machined flaws.

differs in polarity depending on the sensors position with respect to the detected flaw. A two point matched filter consisting of one unit impulse in the positive direction and one in the negative direction separated by $d$ is used to analyze the circumferential signal. The peak absolute value of the correlation in the $41_{d}$ range around the location of the detected defect determines the magnitude of the circumferential indicator, $a_{c}$. The sign determines to which side of the sensor the defect is centered. A defect that passes precisely under the sensor would have a value of near zero; however, only a small deviation from center produces a signal. The metric for the circumferential sensor is most useful in determining whether some interpolation between two sensor sets for a flaw that passes between two of the shoes around the pipe should be used.

Multiple sets of sensors surrounding the pipe may detect the same flaw if the flaw is large enough or wide enough. The software algorithm attempts to group sensor data if a flaw is detected on multiple shoes. If the position of a flaw on adjacent sensors is within a specified tolerance of one another, they are grouped. For the data processed for this paper, we used a tolerance of $8 \mathrm{~mm}$ to account for possible offsets between the sensors shoes. The combined information from all of the sensors for a flaw is presented in a report and chart. Figure 3 represents the chart representation of the information, each parameter plotted versus the sensor position (sensor number three nominally centered over the flaw).

With the ability to detect and abstract information from the data taken with the sensors, we proceed to describing the observations made on 66 artificial flaws inserted into samples of sections of coiled tubing. The flaws included many sizes, shapes, and types of flaws. Flaws were machined, saw cut, impressed, and electrical discharge machined (EDM). Flaws were included both on the outside and inside of the CT pipes. 65 of 66 flaws were automatically detected with the detection algorithm. The one remaining flaw, an $0.58 \mathrm{~mm}$ deep

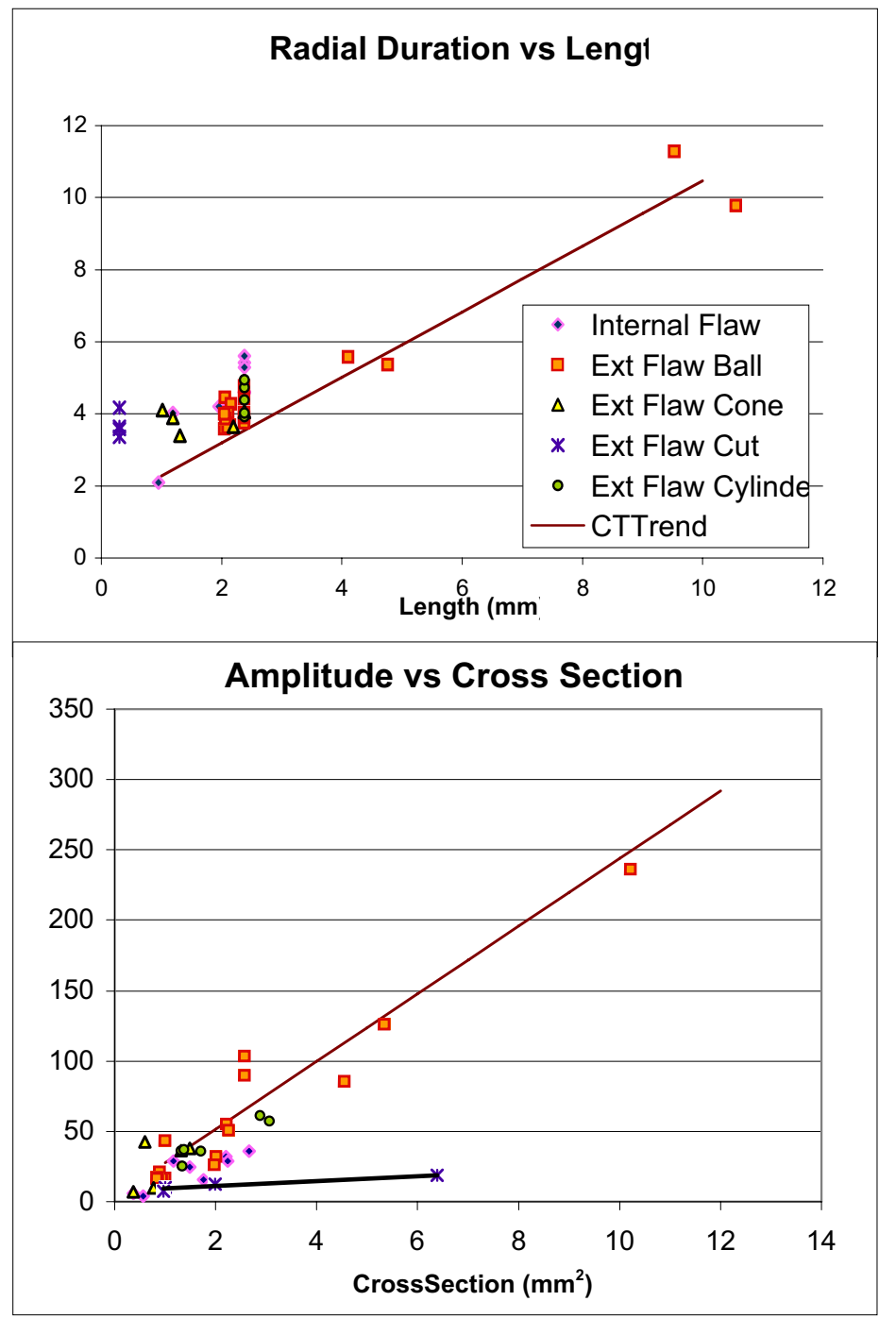

Figure 5. Comparison of duration and amplitude to a more diverse set of flaw including internal, external, and saw cuts.

impressed cone shape, produced a response to the matched filter but was below the chosen threshold. Choosing a threshold low enough to detect this flaw would have produced a large increase in false detections. 


\section{Presentation of Data and Results}

From initial observations of the radial signal duration and the radial signal amplitude using only the sensor centered over the flaw, there were several possible correlations to the flaw geometry. The duration of the radial signal appeared to vary proportionally to the longitudinal length of the flaw. The cross-sectional area of the flaw was associated with the amplitude of the radial and longitudinal signals.

A set of machined flaws inserted into the outside of two tubes was analyzed in detail first. The flaws consisted of ball and flat end mill holes of varying depth; flat end mill slots of varying length and widths; and flat end mill holes of various diameters. Details and summary of abstracted data of all of the flaws are contained in Appendix A. Figure 4 shows the graph of the radial component amplitude versus the cross-sectional area and the radial component duration versus the longitudinal length of the flaws. A reasonable linear fit is produced on both graphs $\left(\mathrm{R}^{2}\right.$ values of 0.955 on the amplitude graph and 0.925 on the duration graph). The points on the length graph are nearly exactly linear as the length increases. There is more variation in the distribution for flaws of shorter length. The trend is for flaws of various depths to be underestimated by applying the linear estimation and for slots of varying circumferential width to be over estimated. Note these flaws have a circumferential dimension of greater than the length dimension but have a length dimension large enough that it does not approximate a crack. In a comparison of the crosssectional area versus amplitude there is also a reasonably good fit. However, the apparent variances occur in the larger area flaws. Two observations are made: 1. The flaws that are generated by end mills of varying diameter and slots of varying circumferential width would best fit different lines. 2 . There is an increase of amplitude within the set of flaws with the same cross-sectional with increasing longitudinal length. These two observations show that the volume of the flaw has some effect on the amplitude (i.e. there is a second order affect on the amplitude due to the volume of material absent in flaws created with mill tool diameters between $2.38 \mathrm{~mm}$ and 6.35 $\mathrm{mm}$. These results present a fairly straightforward picture.

The next set of samples complicates the picture. A more diverse set of flaws that were inserted in additional pipes by machining, impressing, sawing and EDM. A larger variety of shapes were used including: ball, cone and saw cut. EDM flaws were inserted on both the inside and outside of the pipe. The plots of the comparison of amplitude to cross-sectional area and signal duration to length of flaws were completed on these samples as well. Figure 5 contains the graphs of the results for these flaws. The linear fits from the previous set of flaws were plotted with this data. The fits for the duration of longer (longitudinal) flaws support the linear fit. Shorter flaws tend, on average, to be oversized by applying the linear fit equation of related signal duration to length. The most important observations were made from the comparison of amplitude to cross-sectional area. The first is that internal flaws fall consistently below the trend line. The variation is not extreme and a conservative estimate of size could assume an internal flaw for sizing purposes. A possibility exists for a separate sensor that would not be sensitive to internal flaws be used to discriminate between internal and external flaws.

The more serious observation is for the results from saw cuts that approximate cracks. A linear fit for these flaws shows a slope much lower than that of the other types of flaws. A crack is arguably a more severe type of flaw for reducing the longevity of a CT string. To be conservative in attempting to determine the severity of a detected flaw, it would have to be assumed to be a crack. This would produce the affect that a small pit would be classified as a crack and a CT string be taken out of service or repaired prematurely. This result furthers the argument that the volume of the material missing is related to the amplitude of the response. When the length of the flaw is very small, it is no longer a second order factor but becomes the primary factor.

Resolving this issue is extremely important to accurately determining the severity of a flaws effect on the CT durability. Unfortunately, the duration of the signal does not discriminate between a pit and a crack (i.e. a small pit does not have a longer duration than a crack. As with the internal flaws an independent means for determining a crack versus another type of flaw could potentially resolve this issue. A subtle observation of the amplitude versus the circumferentially position of the sensors distributed around the pipe is shown in Figure 6. The decrease in amplitude of the MFL signal out circumferentially from the center of the flaw is less on the saw cut as compared to the ball end-mill produced pit that produces approximately the same amplitude response on the center sensor. There may be some potential to discriminate using the distribution of the amplitude with respect to the circumferentially distributed sensors. This is the most promising observation in the current data sets for a potential to resolve this issue. 

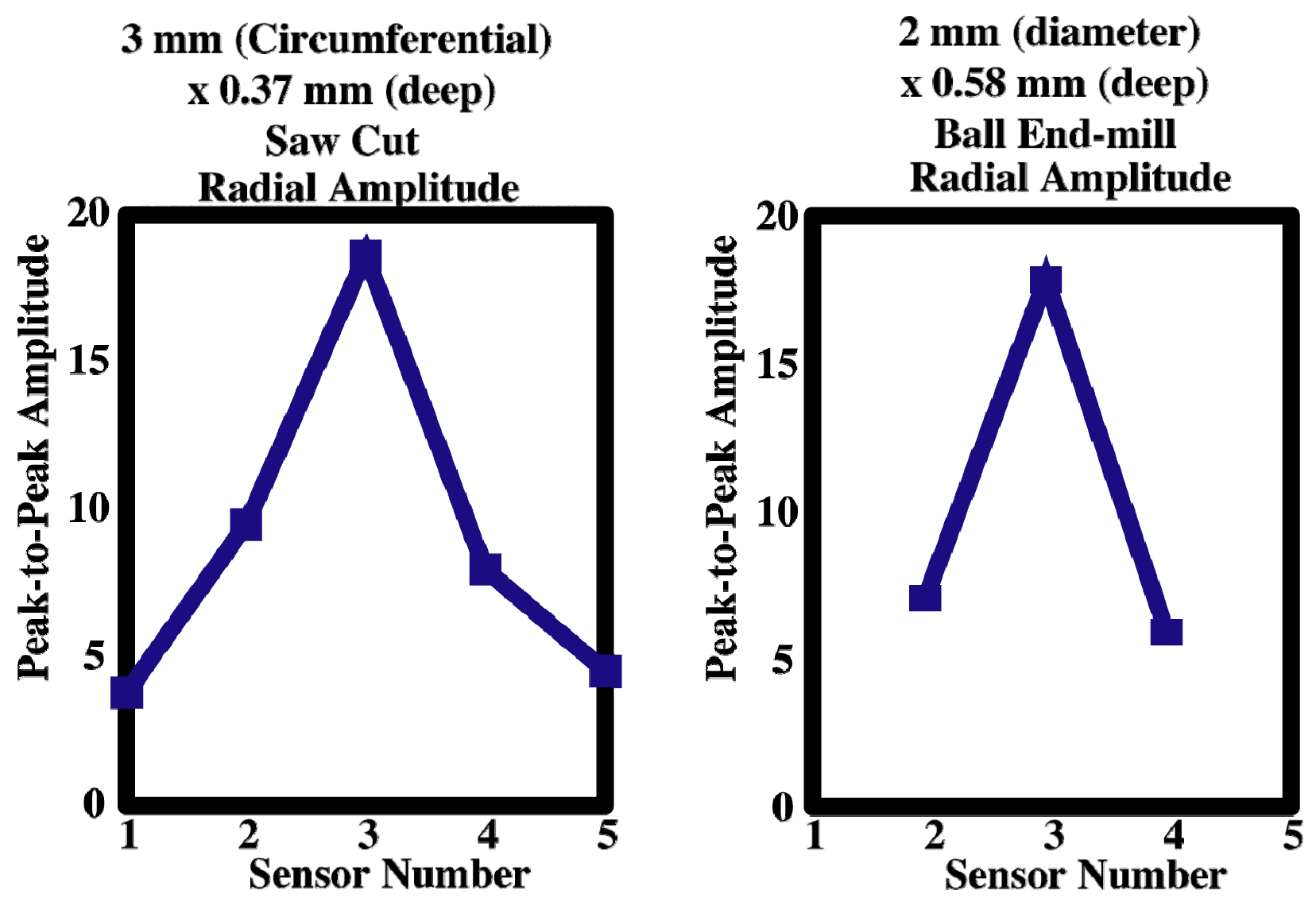

Figure 6. Comparison of the amplitude of a simulated pit and simulated crack. The amplitude of the radial component is shown versus the circumferential position of the sensor shoes. Although each has approximately the same amplitude on the center sensor the amplitude of the pit decreases faster and is not even detected at sensor numbers 1 and 5 .

\section{Conclusions}

This paper presented the observations on the ability to determine geometry of flaws in coiled tubing from MFL data. An algorithm to effectively automatically detect and extract information from the flaw data with a matched filter was described. From the resulting data points for 65 artificial flaws observations were made about the signals versus flaw length and cross-sectional area. For flaws with length on the order of the $2.5 \mathrm{~mm}$ and larger the peak-to-peak amplitude of the radial component of the MFL is roughly proportional to the crosssectional area. The longitudinal length of the flaw is proportional to the peak-to-peak duration of the radial component of the MFL for flaws greater than $3 \mathrm{~mm}$. There are remaining issues with respect to sizing flaws with low total absent volume. An analysis of the variation with respect to the circumferential position of the sensor with respect to the flaw show some possibility that better circumferential resolution could pay a dividend in resolving cracks from pits. It is likely that a more robust approach may be to apply a sensor that is sensitive to cracks but not to pits. One such possibility is "Föster" method ${ }^{3}$. Future research will include implementing this method.

\section{Acknowledgements}

We gratefully acknowledge the partnership of the University of Tulsa and the University of Tulsa Coiled Tubing Mechanics Research Consortium in the project. Special thanks to Rod
Stanley for the suggestion of the Föster method idea. This work was supported by the Office of Fossil Energy, U.S. Department of Energy, under the Department of Energy's Idaho Operations Office Contract DE-AC07-05ID14517.

\section{References}

1-Tipton, S.M.:'Multiaxial Plasticity and Fatigue Life Prediction in Coiled Tubing," in Fatigue Lifetime Predictive Techniques: $3^{\text {rd }}$ Volume, ASTM STP 1292, American Society for Testing and Materials, 1996, pp. 283-304.

2-McJunkin, T.R, et al.: "Detection of Coiled Tubing Defects Using Matched Filter Algorithm", NDE\&T International, Submitted September 2005.

3-Föster F.: "On the Way from "know-how" to the "knowwhy" in Magnetic Leakage Field Method of Nondestructive Testing," Chinese Journal of NDT, 1997, 19 (11), pp. $347-$ 350 . 


\section{Appendix}

This appendix provides the measurements of the signals from each of the flaws analyzed in the article.
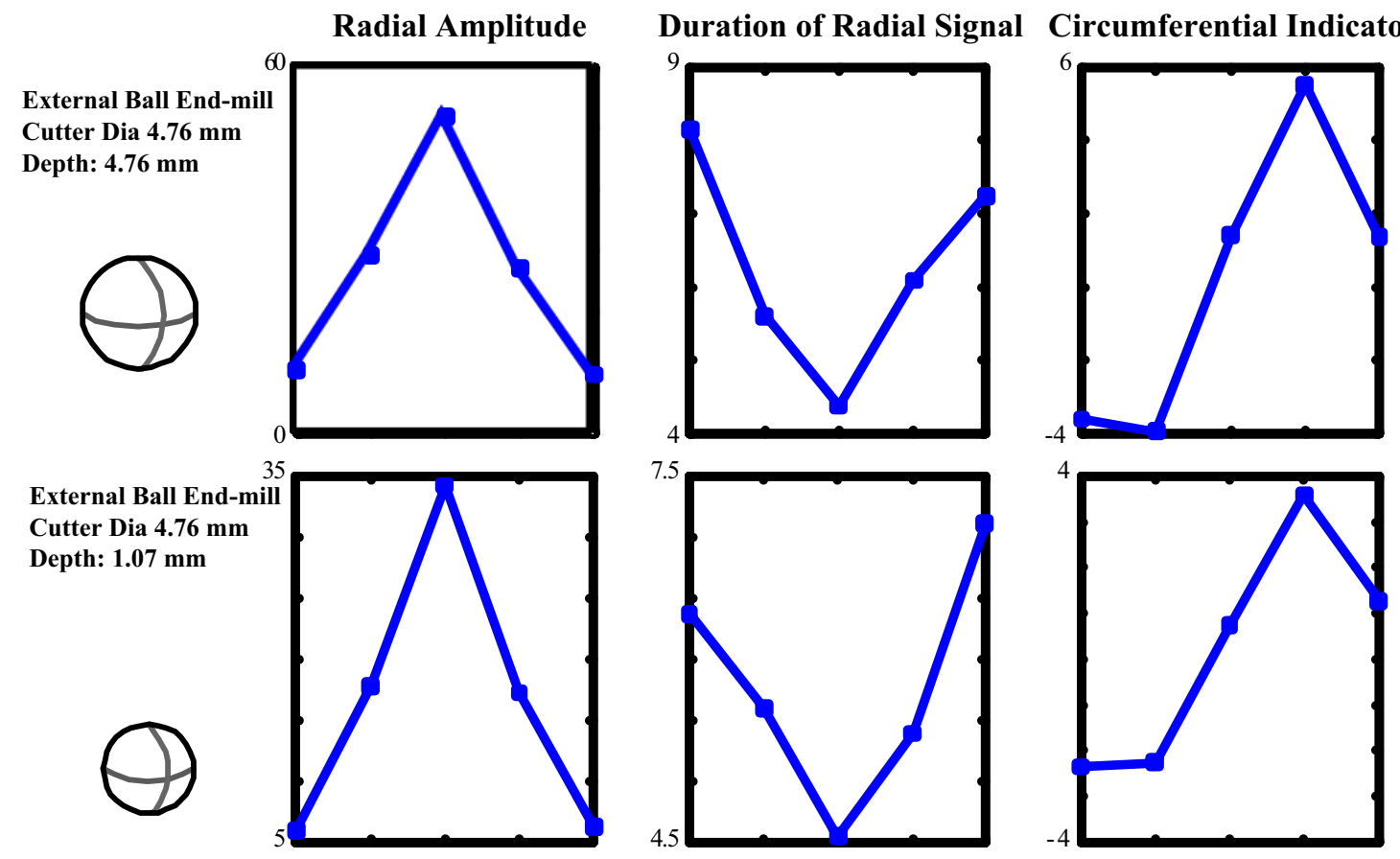

Longitudinal Amplitude
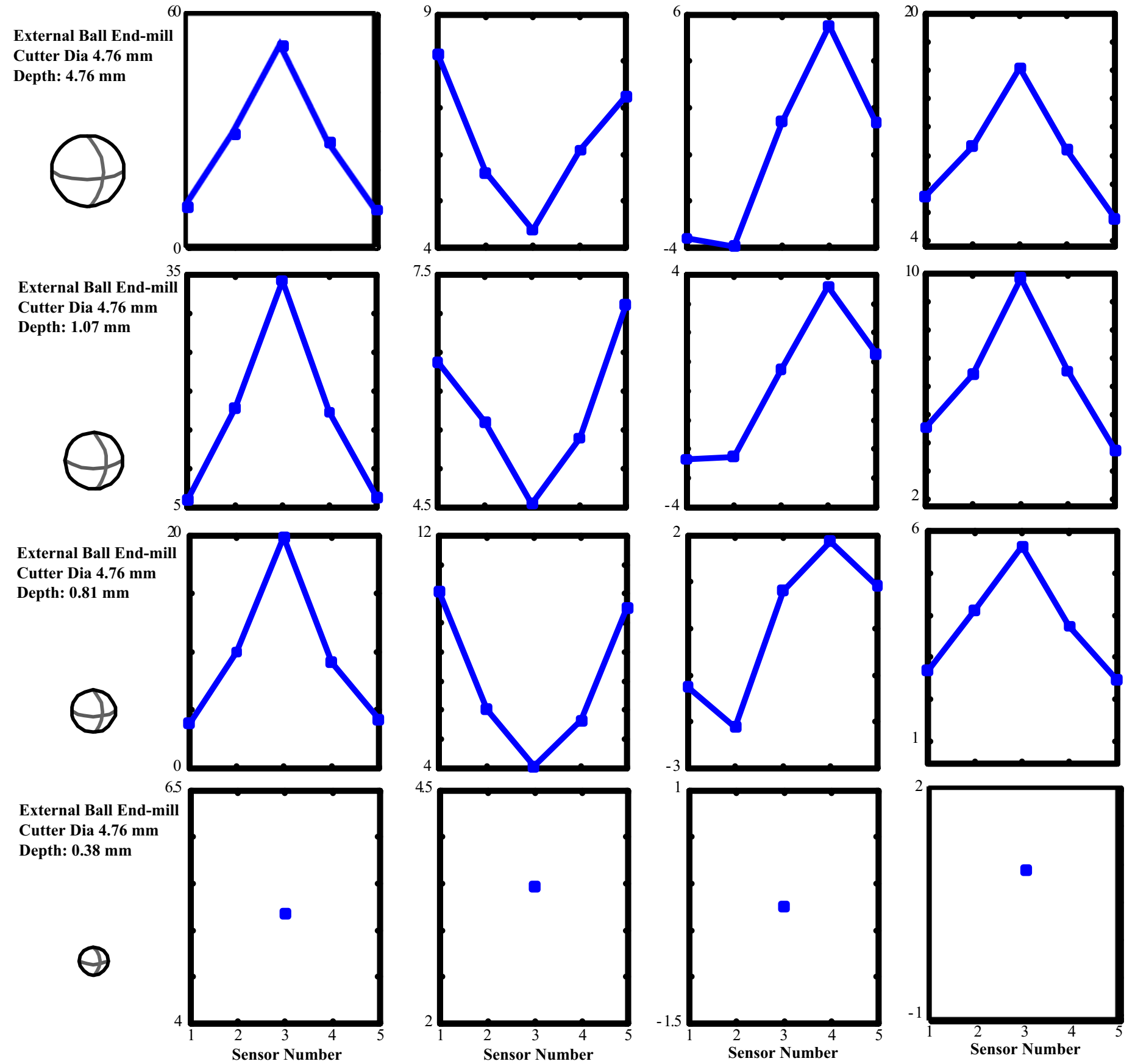

Cutter Dia $4.76 \mathrm{~mm}$ Cutter Dia 4.76
Depth: $1.07 \mathrm{~mm}$

External Ball End-m
Cutter Dia $4.76 \mathrm{~mm}$
Depth: $0.81 \mathrm{~mm}$
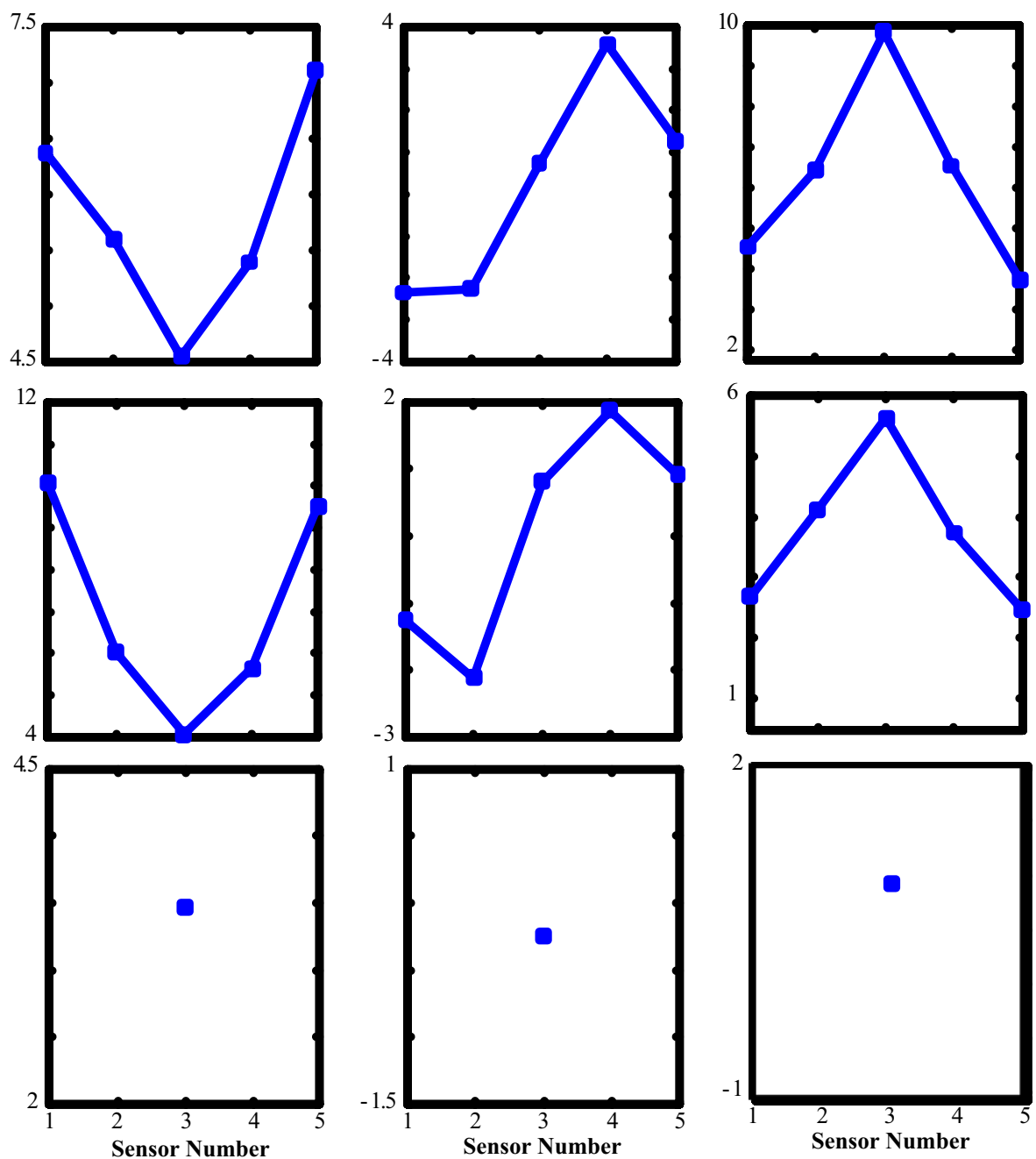
Radial Amplitude

External Flat End-mil Cutter Dia 4.76 mm

Depth: $1.58 \mathrm{~mm}$
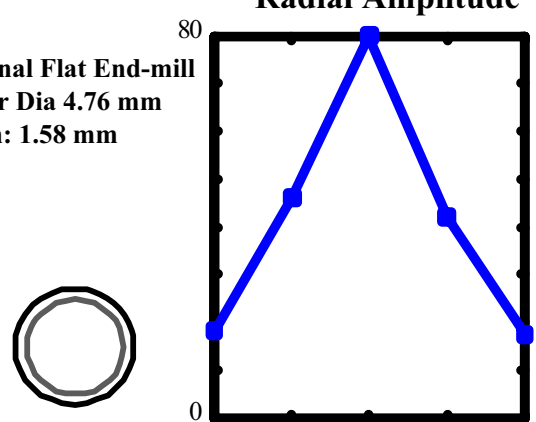

External Flat End-mil Cutter Dia 4.76 mm

Depth: $1.17 \mathrm{~mm}$<smiles>C1=C=CC=C=C=CC=C=1</smiles>

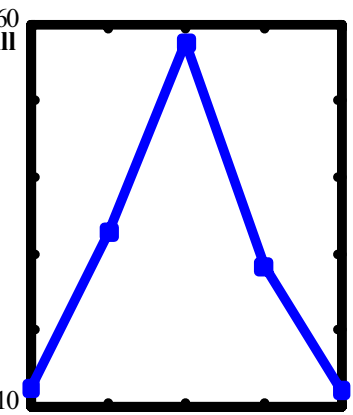

External Flat End-mil Cutter Dia $4.76 \mathrm{~mm}$ Depth: $0.79 \mathrm{~mm}$
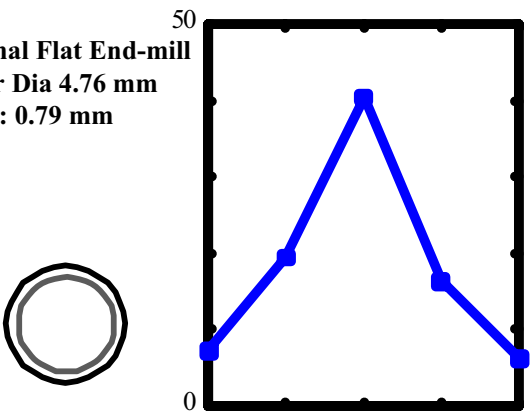

External Flat End-mill Cutter Dia $4.76 \mathrm{~mm}$ Depth: 0.38 mm

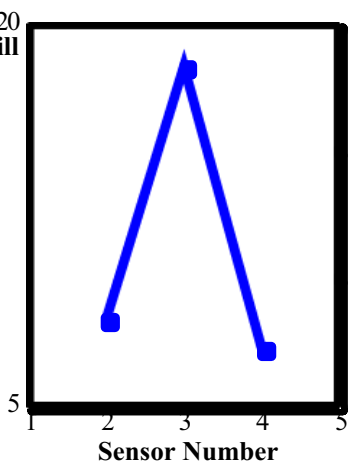

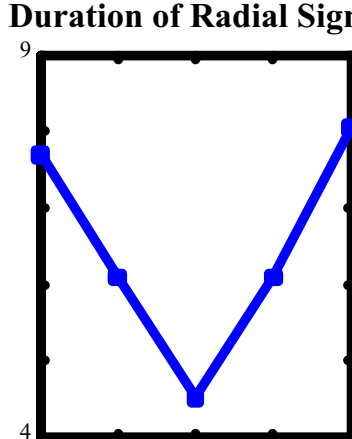
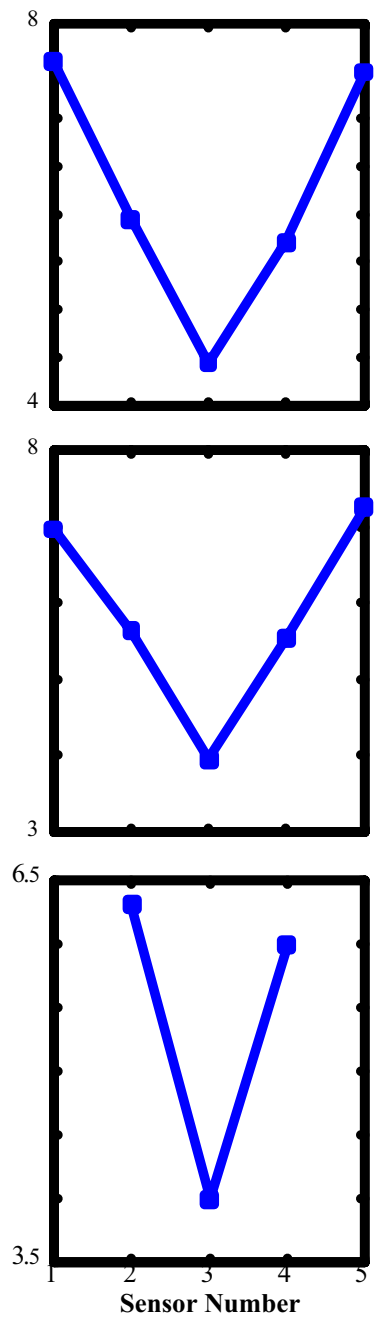

Longitudinal Amplitude
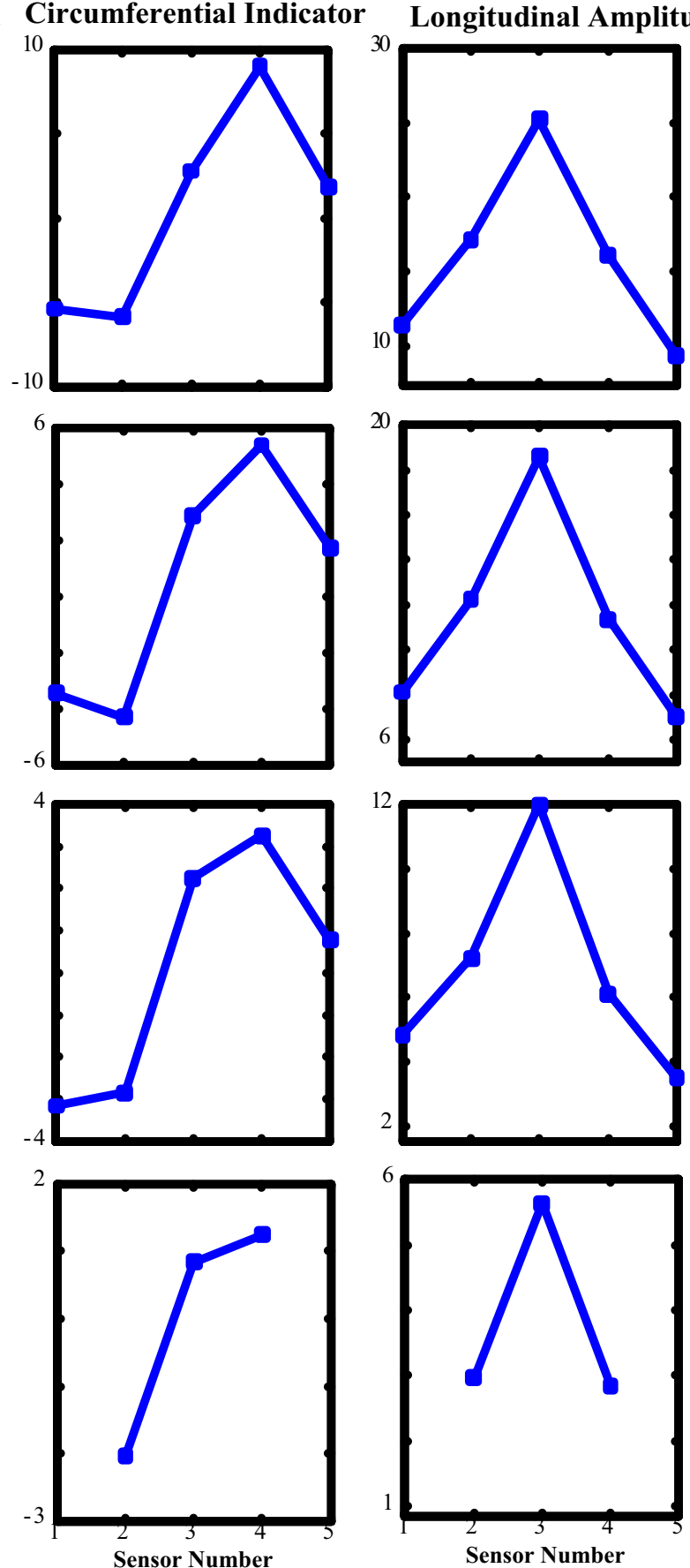


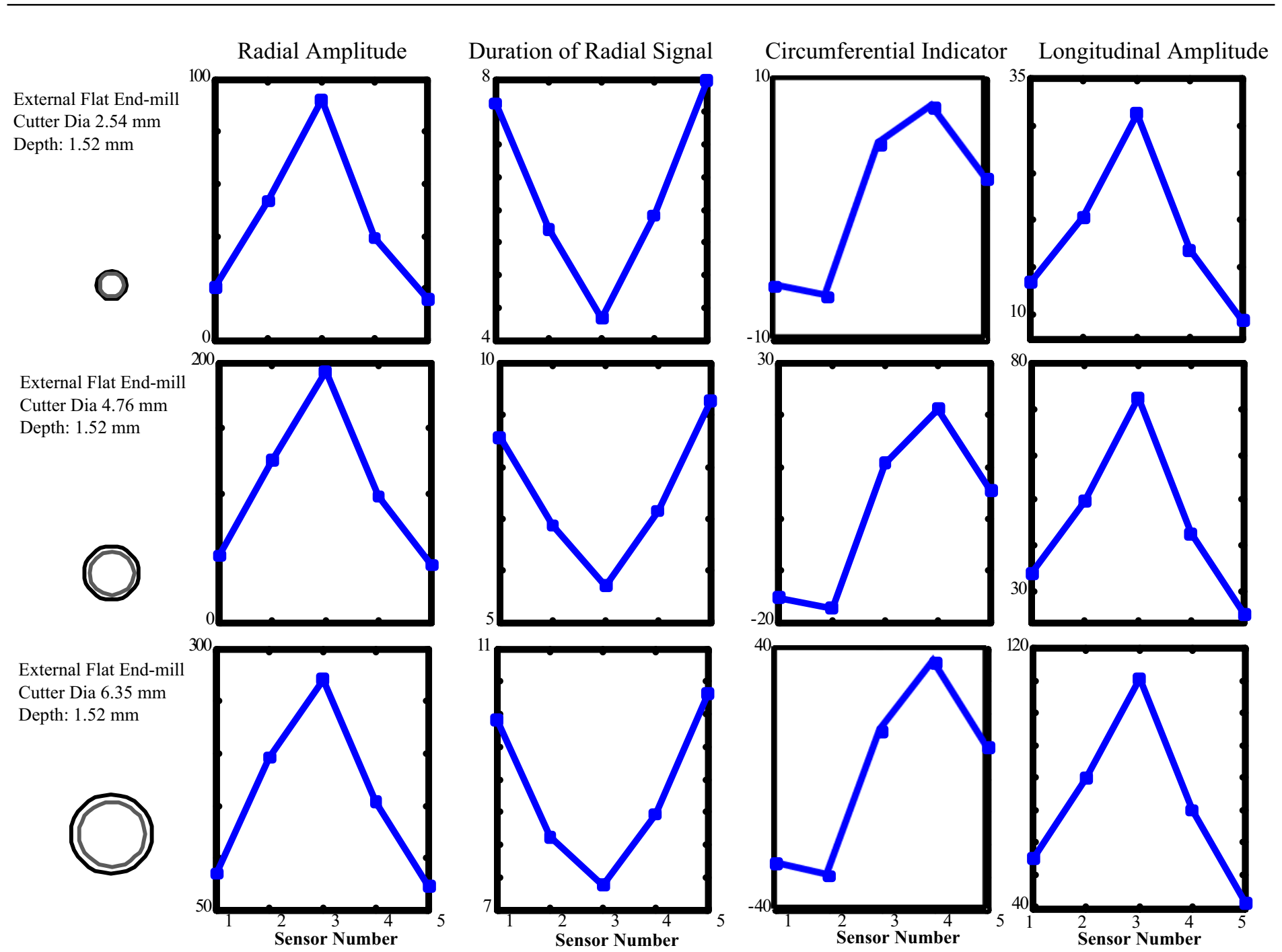



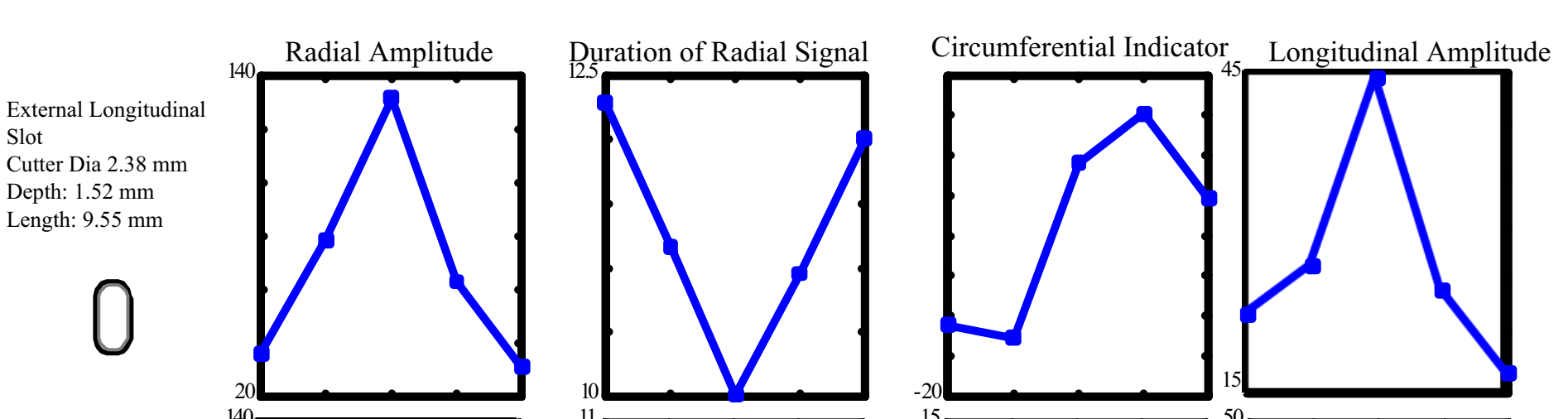

External Longitudinal Slot

Cutter Dia $2.38 \mathrm{~mm}$

Depth: $1.52 \mathrm{~mm}$

Length: $7.24 \mathrm{~mm}$<smiles>[18OH]</smiles>
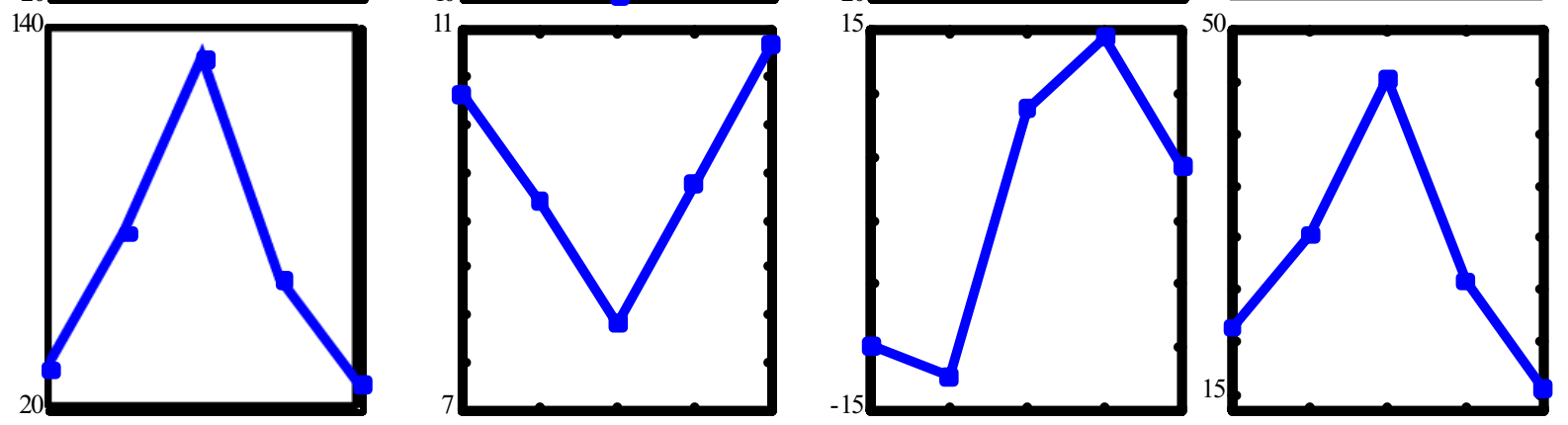

External Longitudinal

Slot

Cutter Dia $2.38 \mathrm{~mm}$

Depth: $1.52 \mathrm{~mm}$

Length: $4.83 \mathrm{~mm}$

O
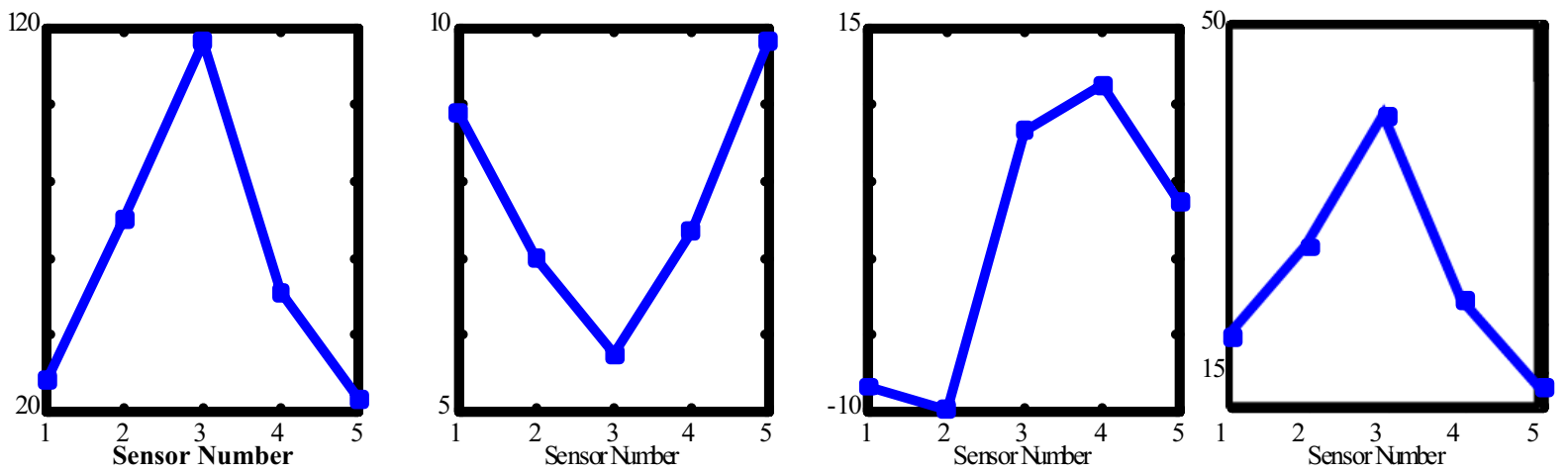
External

Circumferential Slot

Cutter Dia $2.38 \mathrm{~mm}$

Depth: $1.52 \mathrm{~mm}$

Width: $9.55 \mathrm{~mm}$

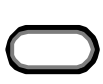

Radial Amplitude

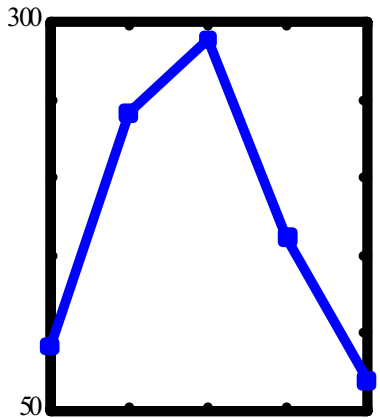

External

Circumferential Slot Cutter Dia $2.38 \mathrm{~mm}$

Depth: $1.52 \mathrm{~mm}$

Width: $7.13 \mathrm{~mm}$

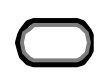

\section{External}

Circumferential Slot

Cutter Dia $2.38 \mathrm{~mm}$

Depth: $1.52 \mathrm{~mm}$

Width: $4.81 \mathrm{~mm}$
Duration of Radial Signal
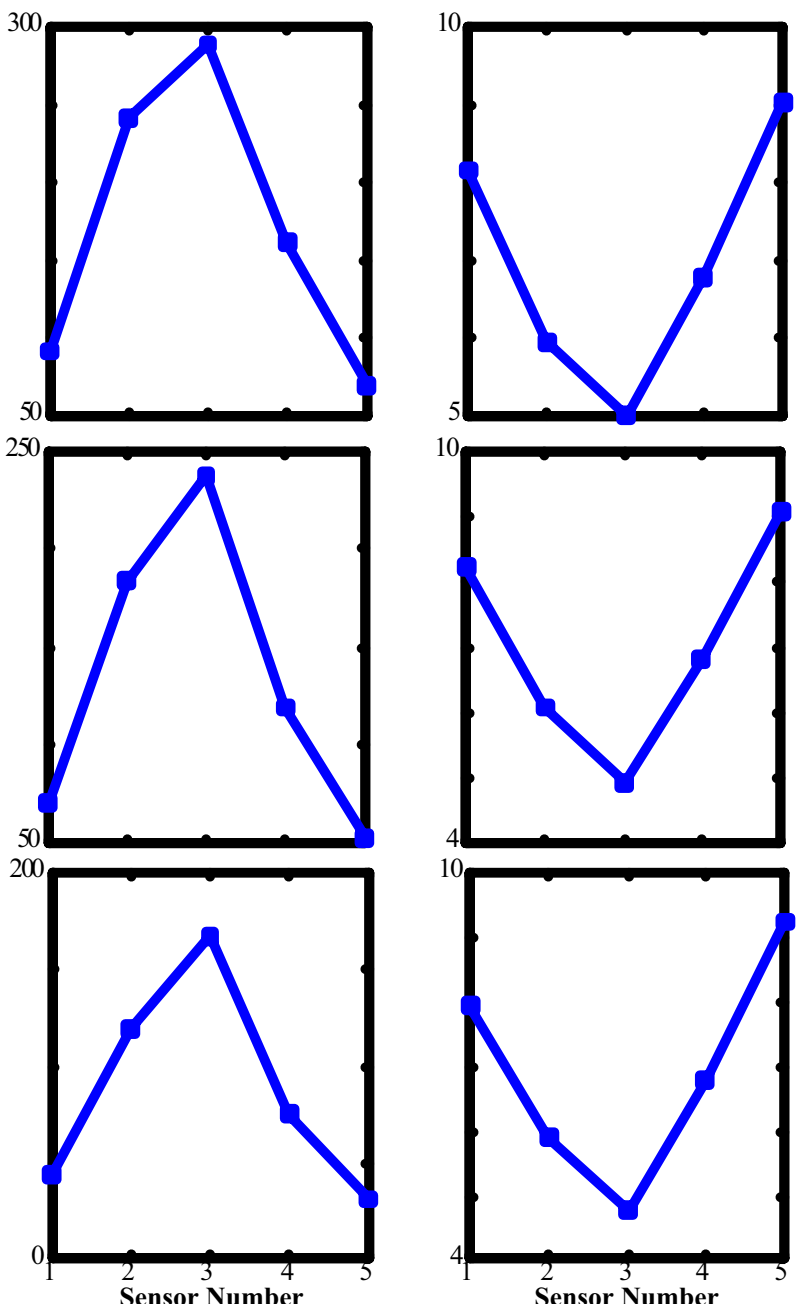
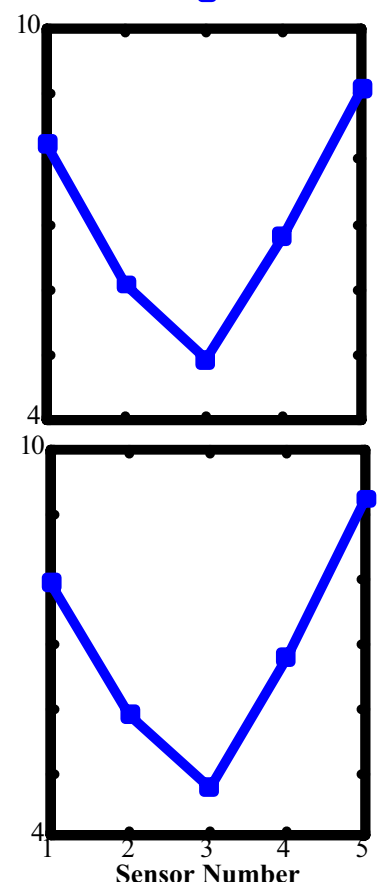

Circumferentail Indicator Longitudinal Amplitude
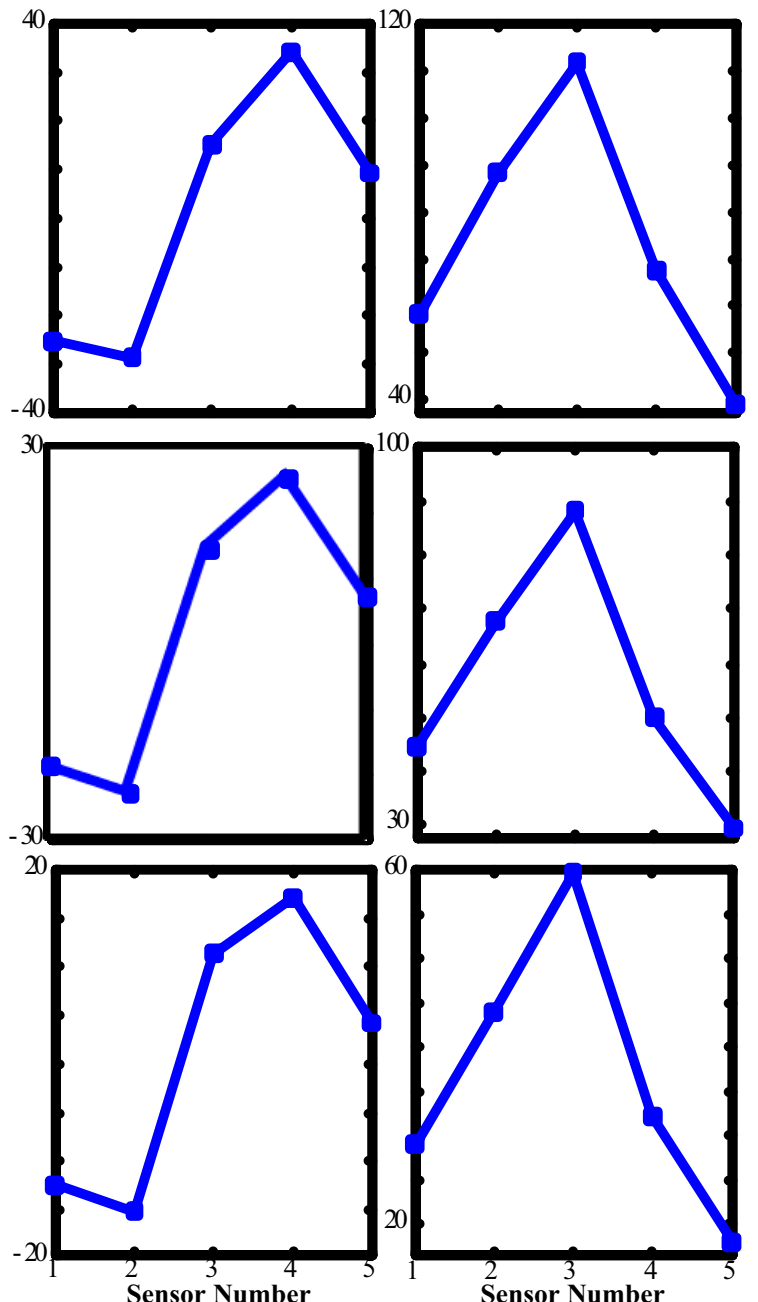
Radial Amplitude

External Ball End-mill Longitudinal Slot Depth: $0.66 \mathrm{~mm}$

Length: $10.56 \mathrm{~mm}$

Width: $2.11 \mathrm{~mm}$

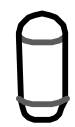

External Ball End-mil Longitudinal Slot

Depth: $0.61 \mathrm{~mm}$

Length: $4.11 \mathrm{~mm}$

Width: 2.05 mm<smiles>C1CC2CCC1C2</smiles>

External Ball End-mill Circumferential Slot Depth: $0.59 \mathrm{~mm}$ Length: $2.06 \mathrm{~mm}$ Width: $4.11 \mathrm{~mm}$
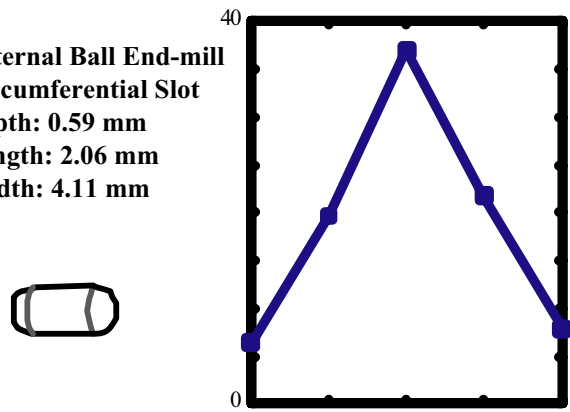

External Ball End-mill CircumferentialSlot Depth: $0.68 \mathrm{~mm}$

Length: $2.15 \mathrm{~mm}$

Width: $8.62 \mathrm{~mm}$
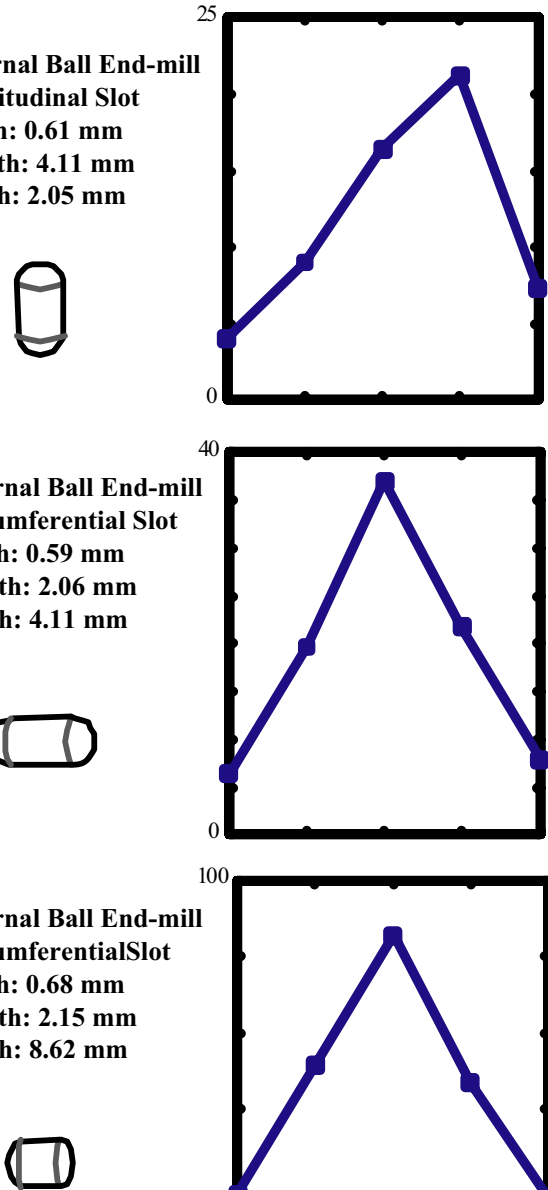

Duration of Radial Signal
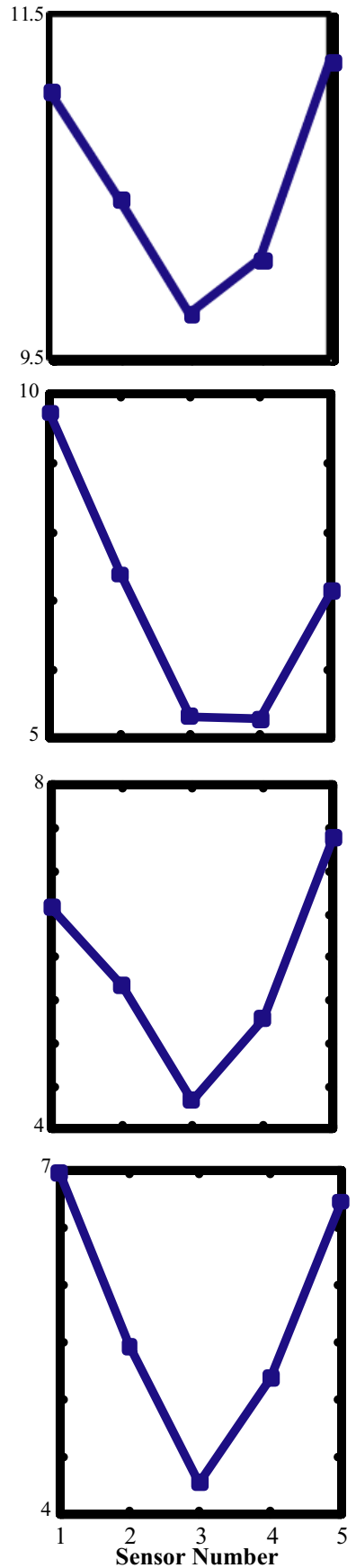

Circumferential Indicator

Longitudinal Amplitude
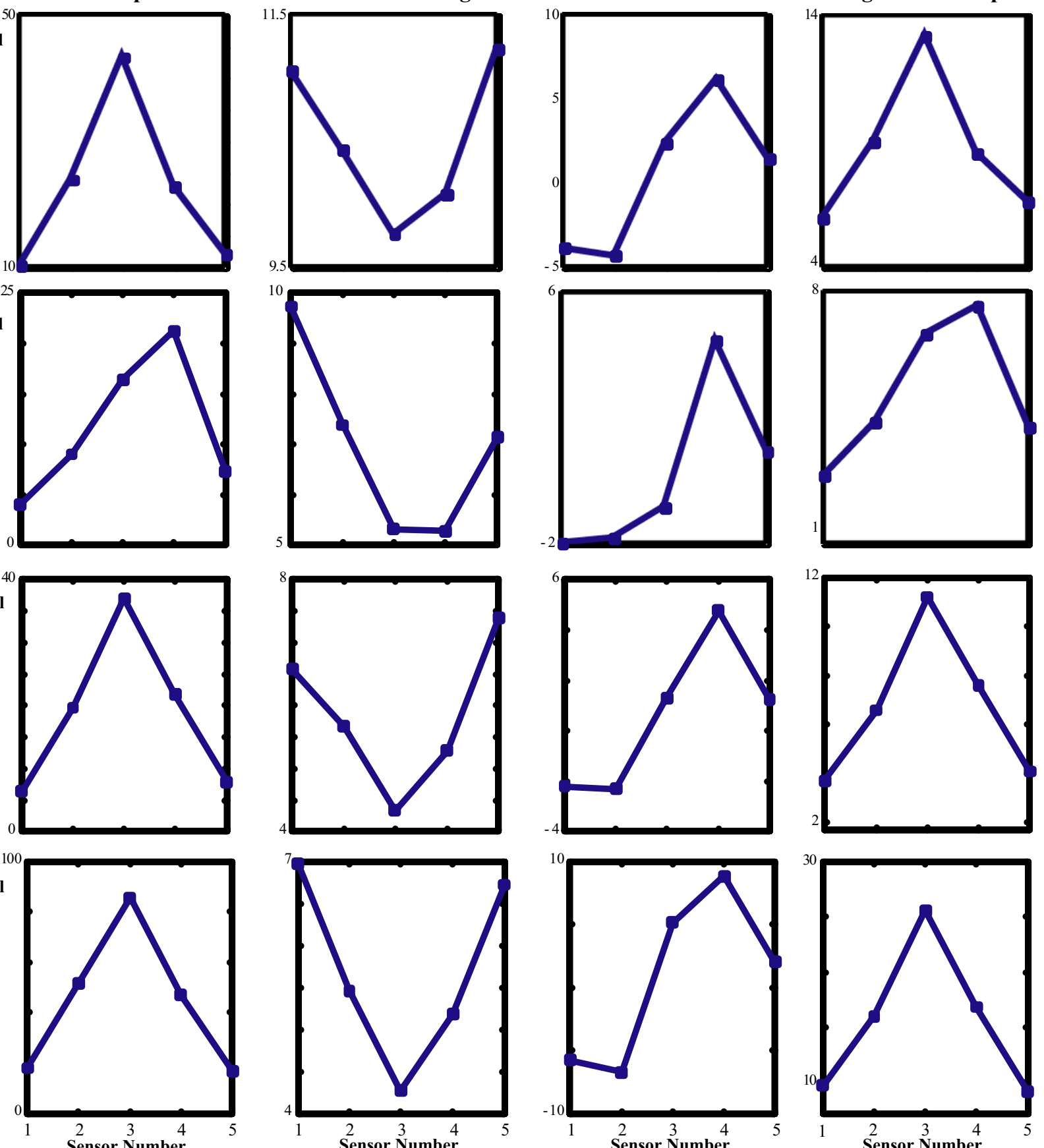
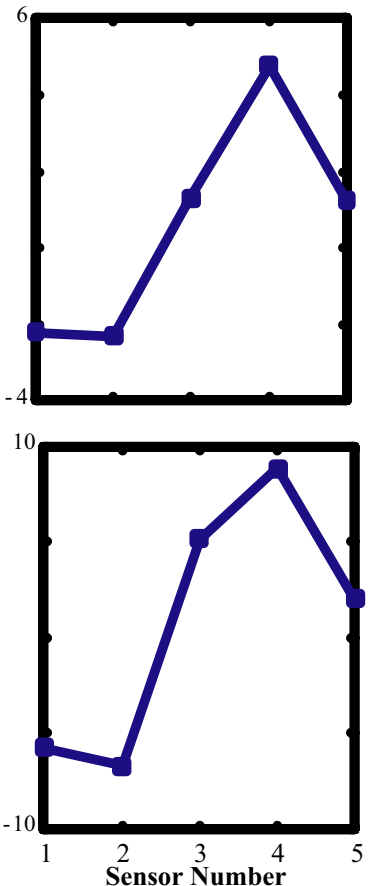
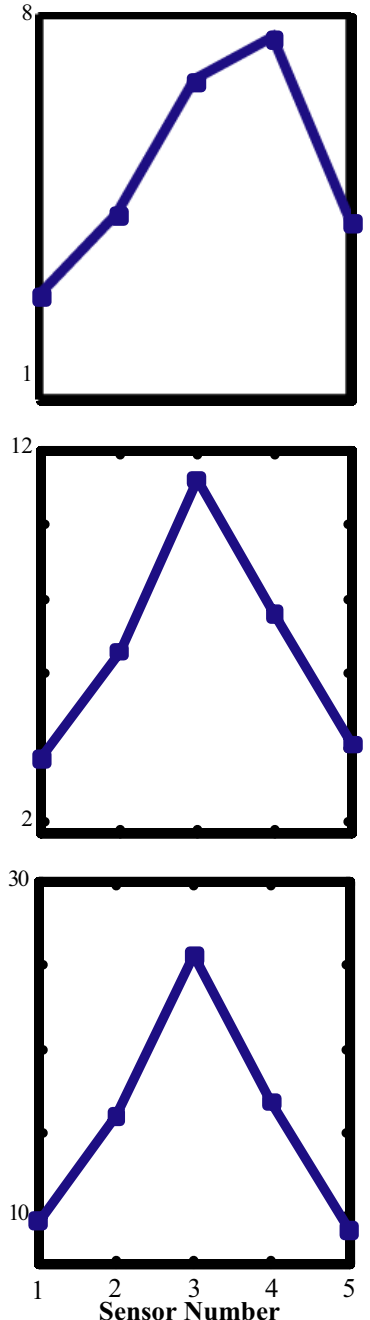
Radial Amplitude

External Ball End-mill Longitudinal Slot Depth: $1.37 \mathrm{~mm}$

Length: $9.53 \mathrm{~mm}$

Width: $2.38 \mathrm{~mm}$
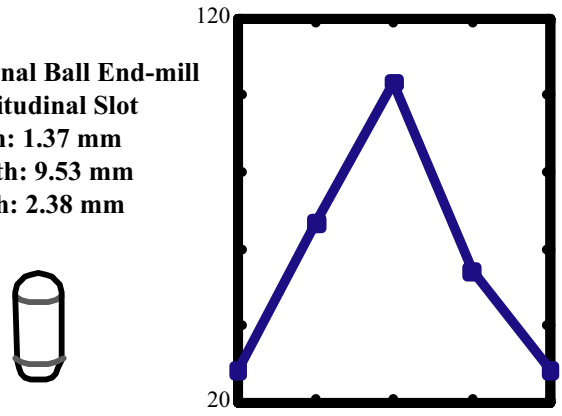

External Ball End-mill Longitudinal Slot Depth: $1.35 \mathrm{~mm}$

Length: $4.76 \mathrm{~mm}$ Width: $2.38 \mathrm{~mm}$<smiles>[C-]1CCCC1</smiles>
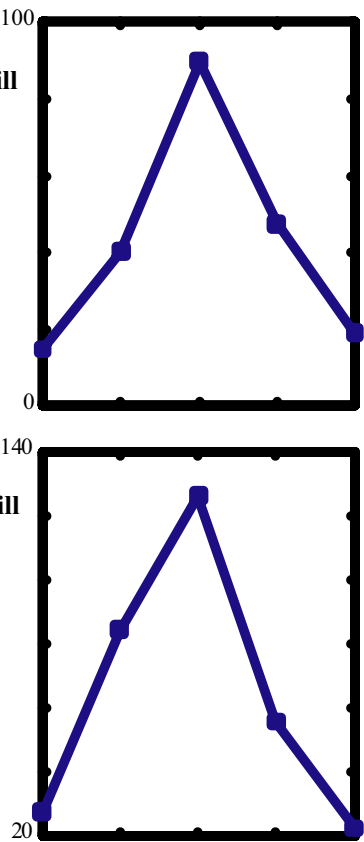

External Ball End-mill Circumferential Slot Depth: $1.29 \mathrm{~mm}$ Length: $2.38 \mathrm{~mm}$ Width: $4.76 \mathrm{~mm}$
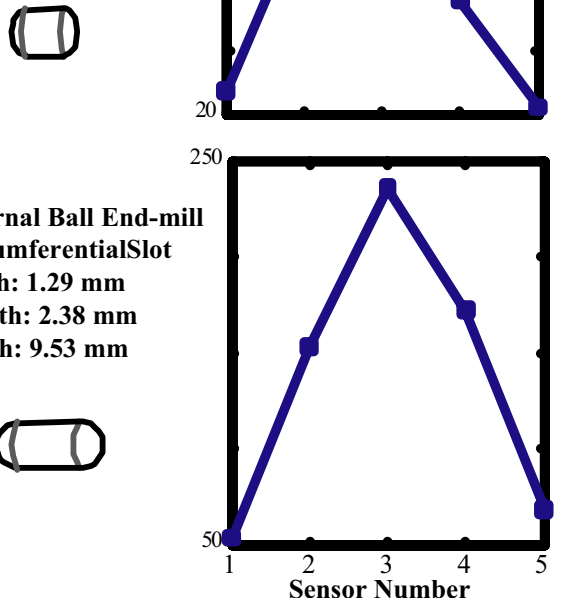

Duration of Radial Signal
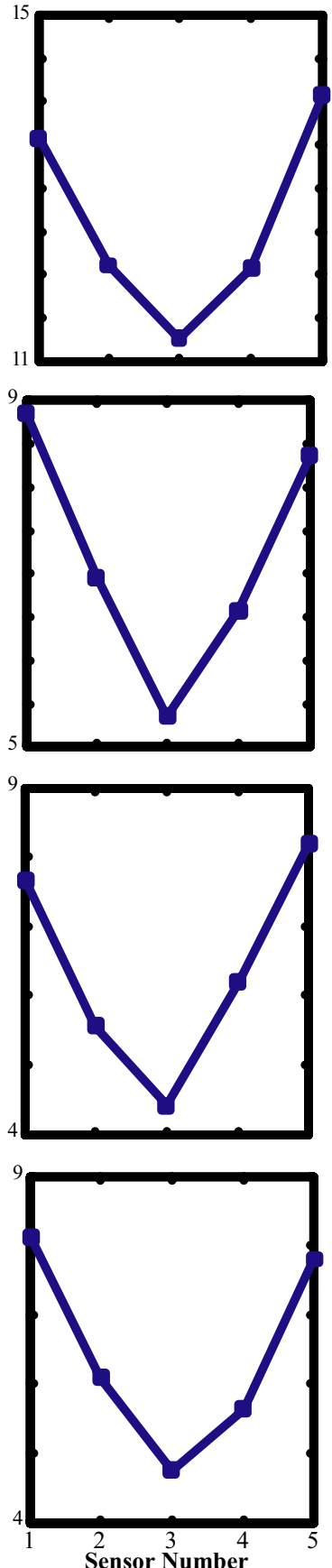

Circumferential Indicator

Longitudinal Amplitude
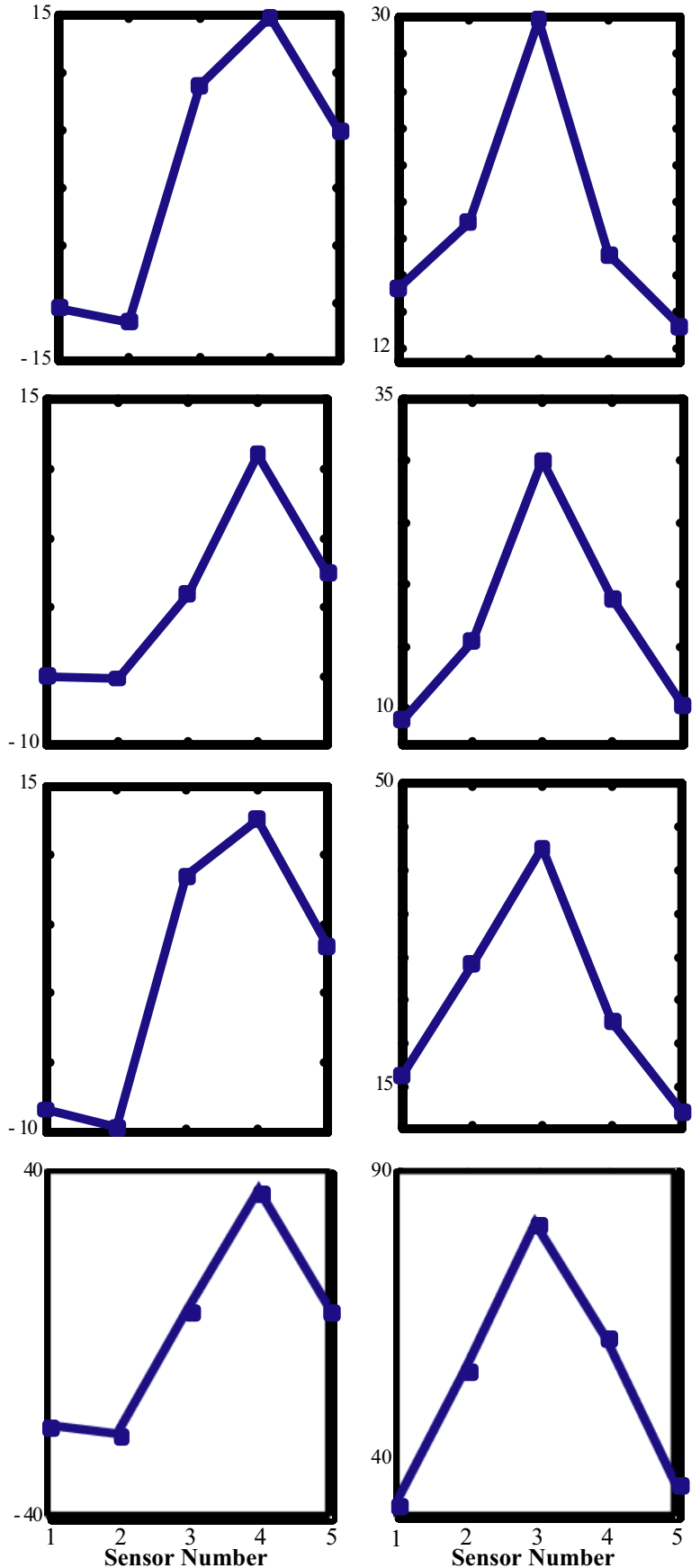
Radial Amplitude

External Ball End-mill Openning Dia $2.0 \mathrm{~mm}$ Depth: $0.58 \mathrm{~mm}$

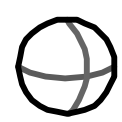

External Flat End-mill Openning Dia $2.38 \mathrm{~mm}$ Depth: $0.58 \mathrm{~mm}$<smiles>C1=C=C=C=C=C=C=C=C=C=C=C=1</smiles>

External Machined Cone

Openning Dia $1.0 \mathrm{~mm}$ Depth: 0.51

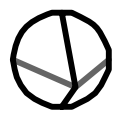

External Saw Cut Width $11.85 \mathrm{~mm}$

Length $0.30 \mathrm{~mm}$ Depth: 0.58

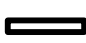

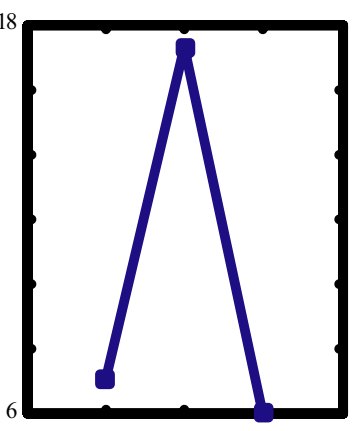
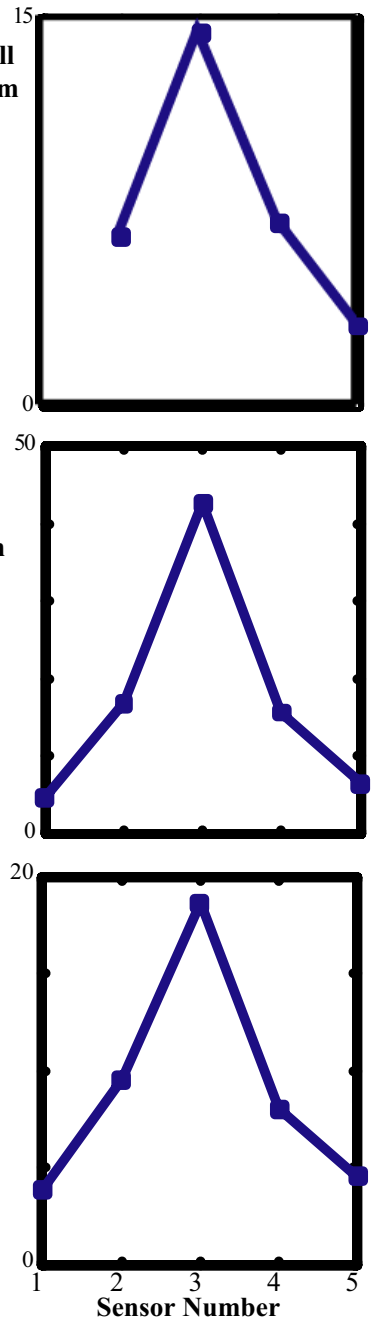

Duration of Radial Signal

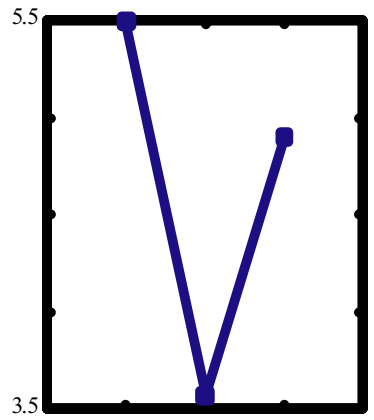

Circumferential Indicator Longitudinal Amplitude
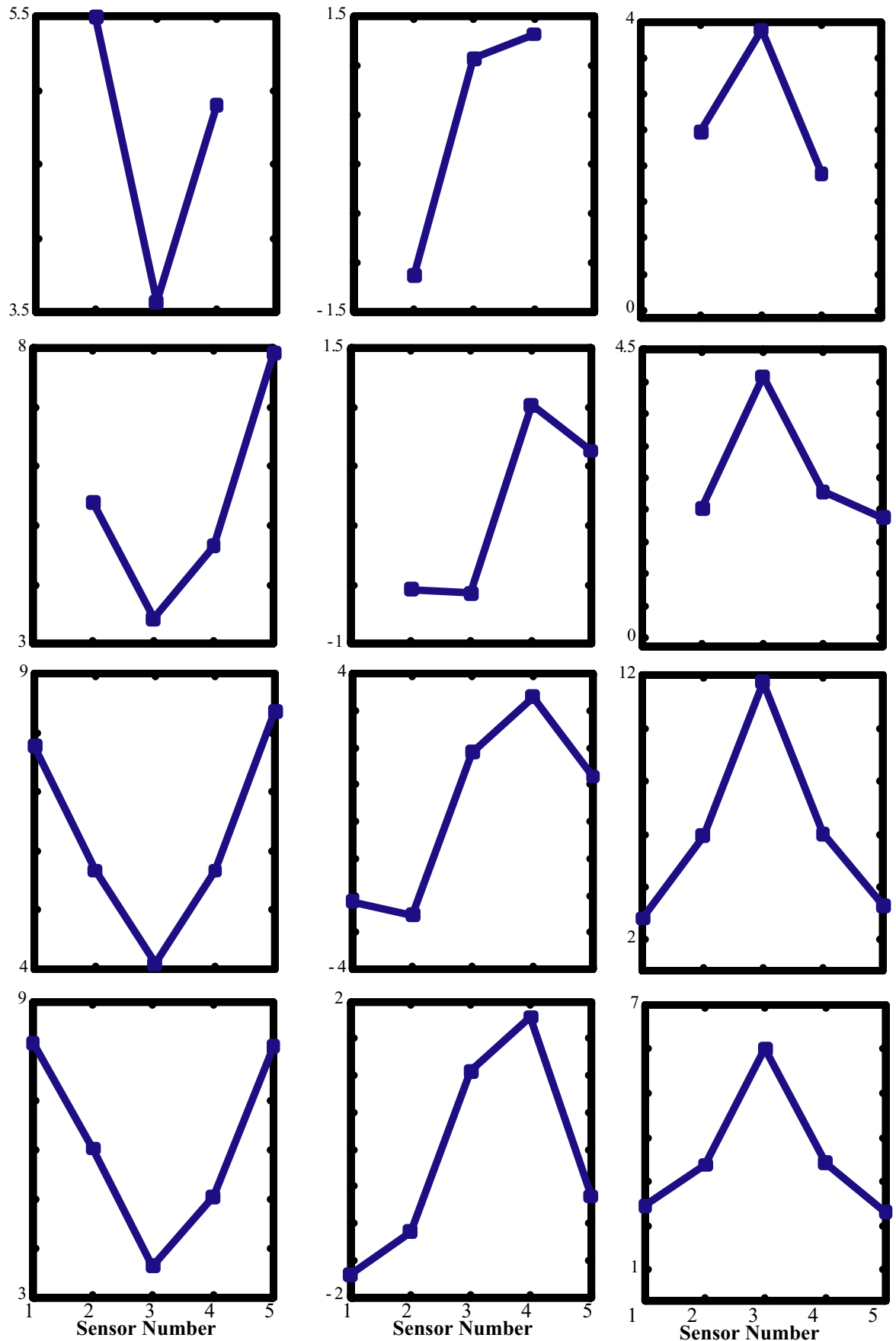
Radial Amplitude

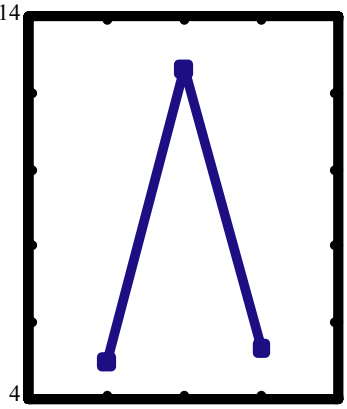

External Saw C

Width 3.05 mm

Length $0.30 \mathrm{~mm}$

Depth: $0.37 \mathrm{~mm}$
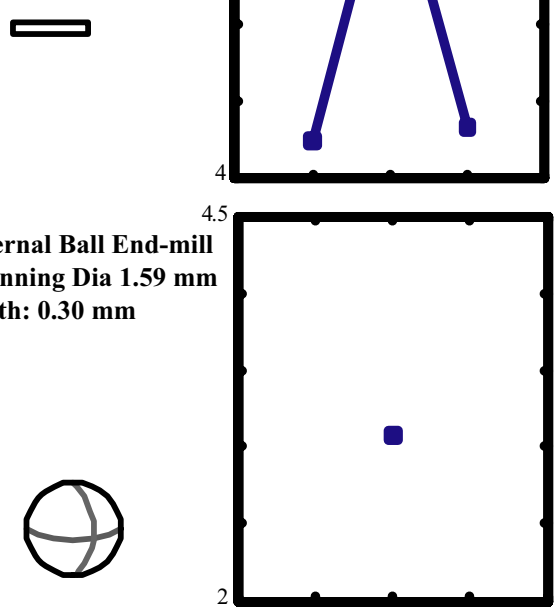

External Ball End-mill Openning Dia $2.38 \mathrm{~mm}$

Depth: $0.41 \mathrm{~mm}$
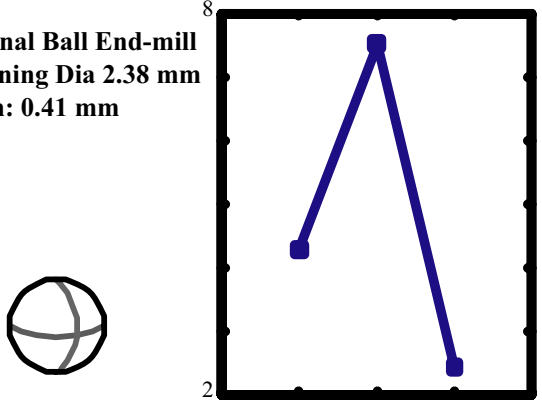

External Ball End-mill Openning Dia $2.11 \mathrm{~mm}$

Depth: $0.67 \mathrm{~mm}$

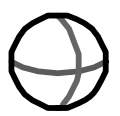

Duration of Radial Signal
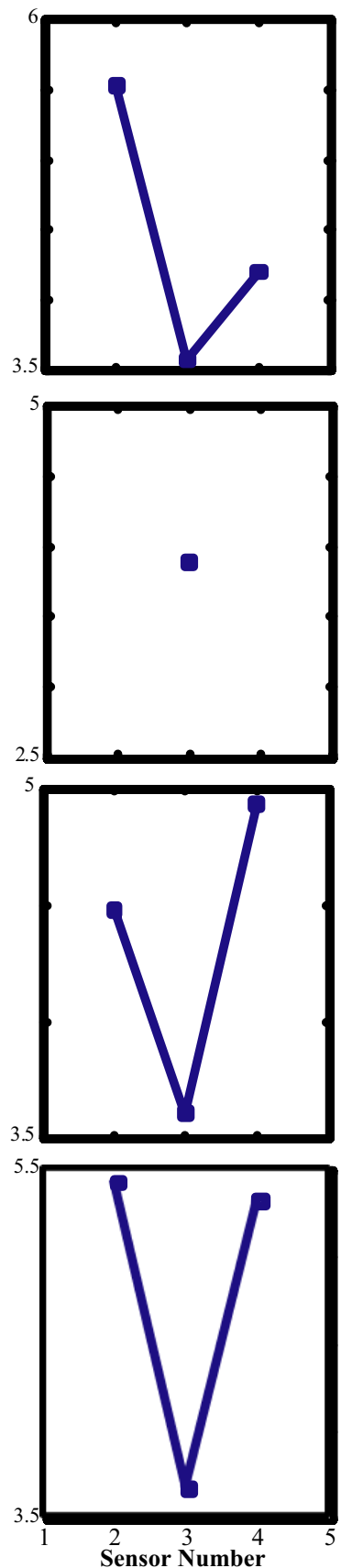

Circumferential Indicator

Longitudinal Amplitude
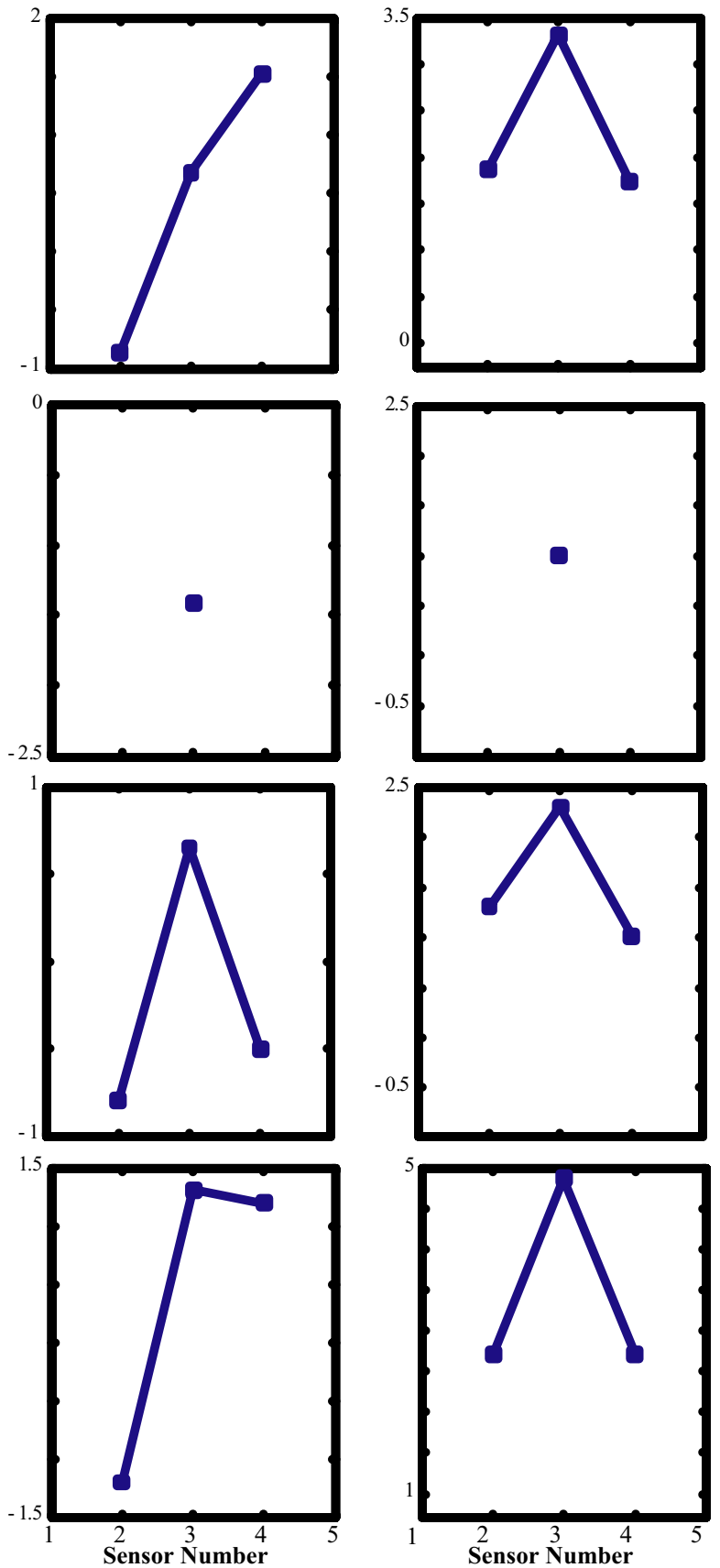

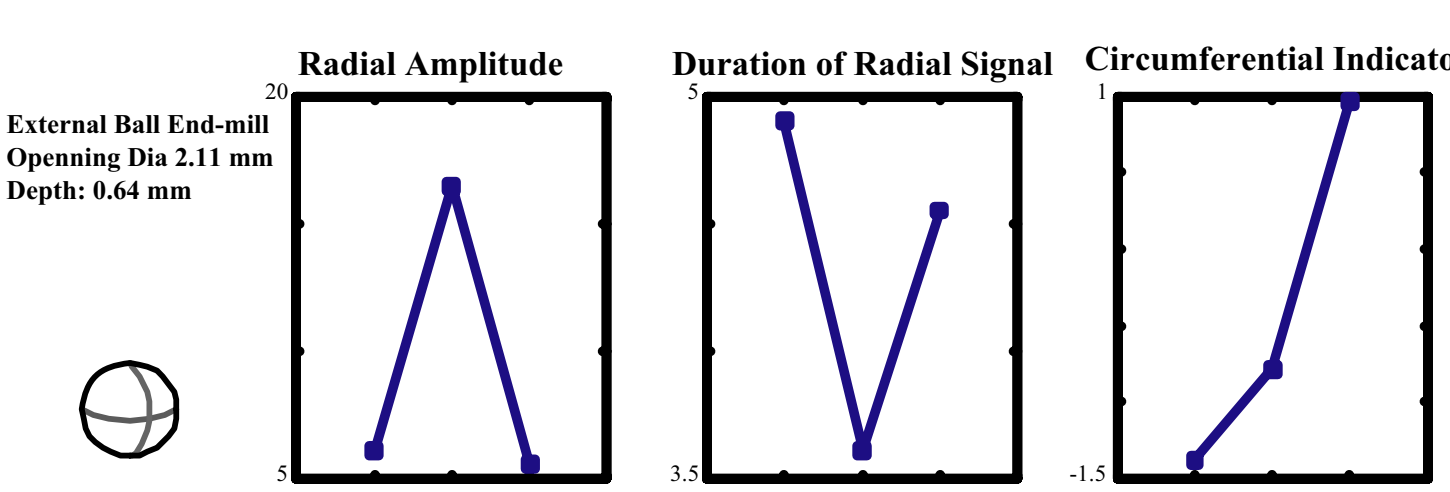

\section{Longitudinal Amplitude} Openning Dia $2.11 \mathrm{~mm}$ Depth: 0.64 mm
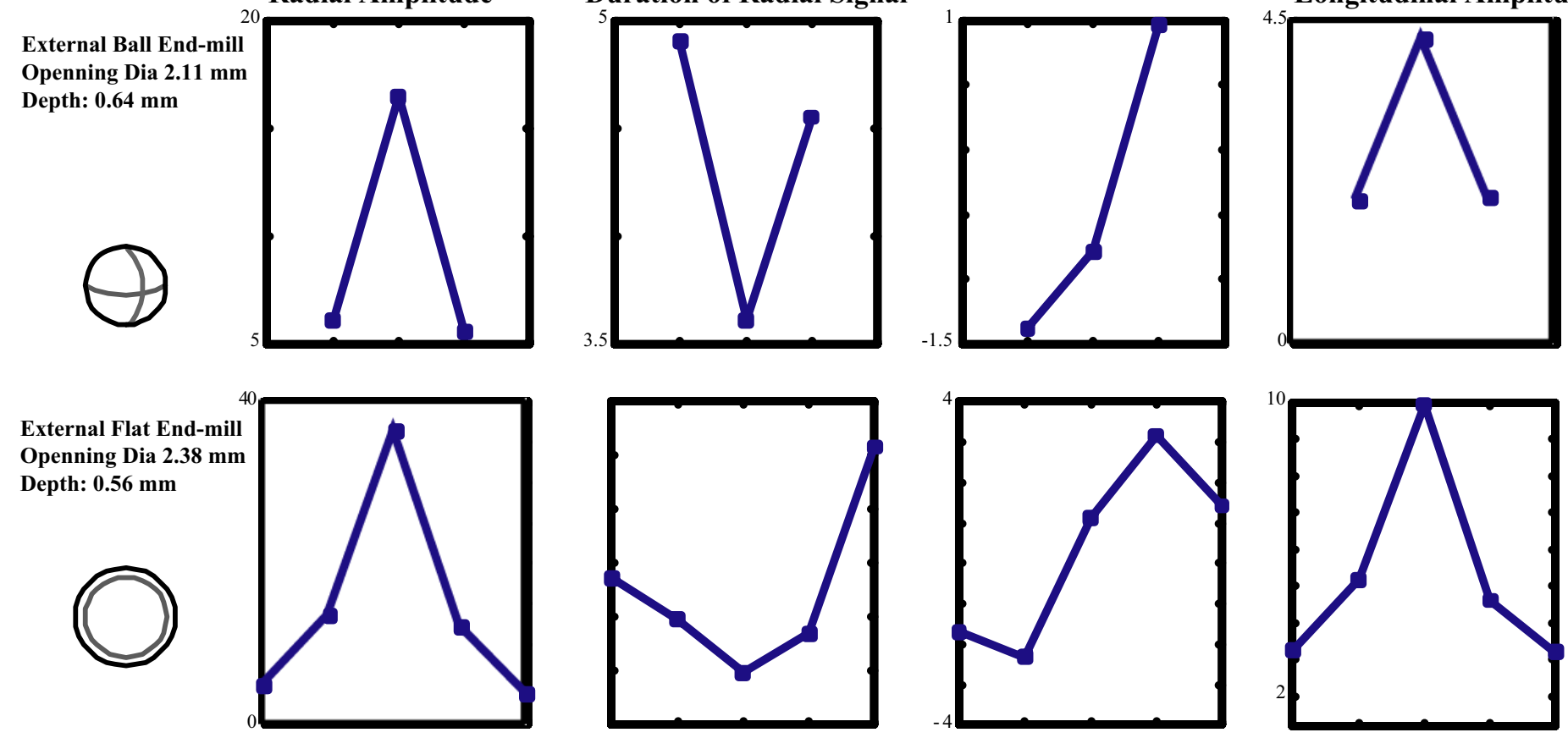

External Saw Cut Diagonal

Width $0.30 \mathrm{~mm}$

Length $6.35 \mathrm{~mm}$ Depth: $0.32 \mathrm{~mm}$
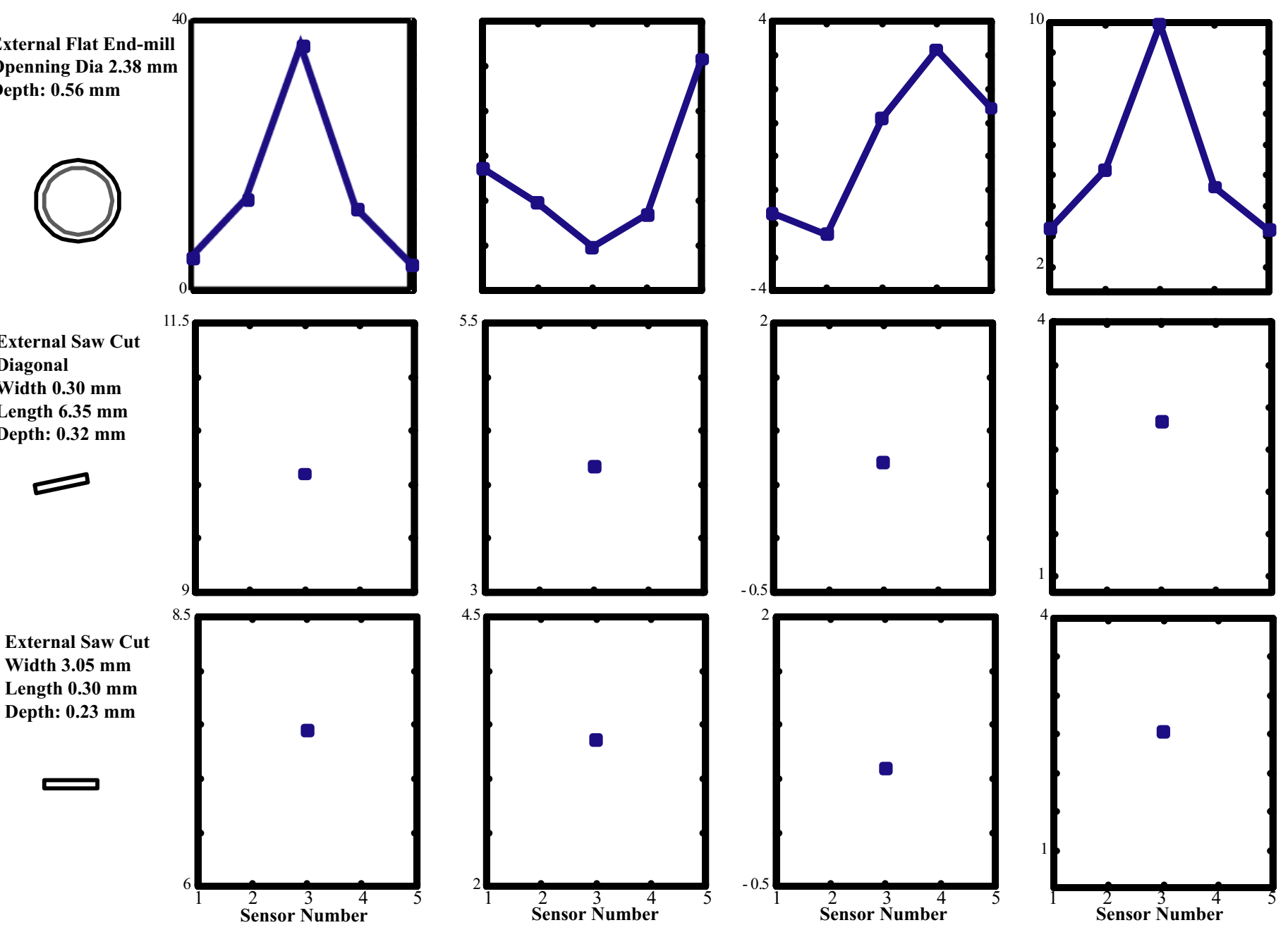

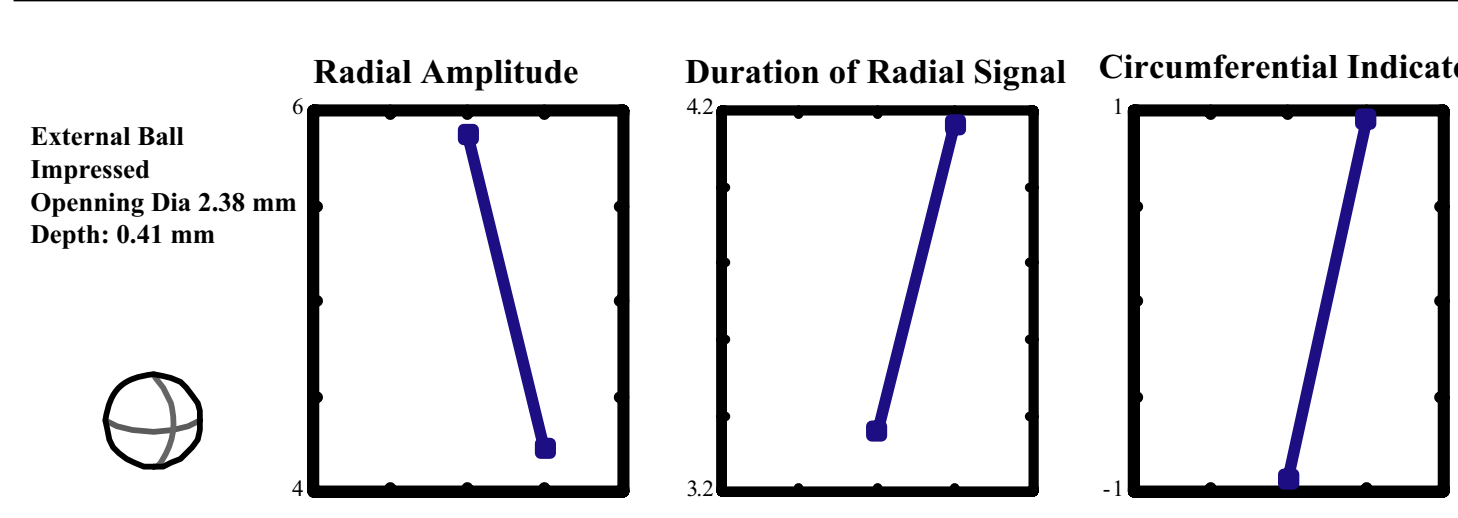

Longitudinal Amplitude

External Cone

Impressed

Depth: 0.58

Not detected.

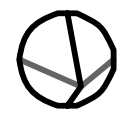

External Ball

Impressed

Depth: $0.58 \mathrm{~mm}$

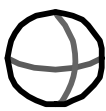

External Ball Impressed

Openning Dia $2.37 \mathrm{~mm}$ Depth: $1.09 \mathrm{~mm}$
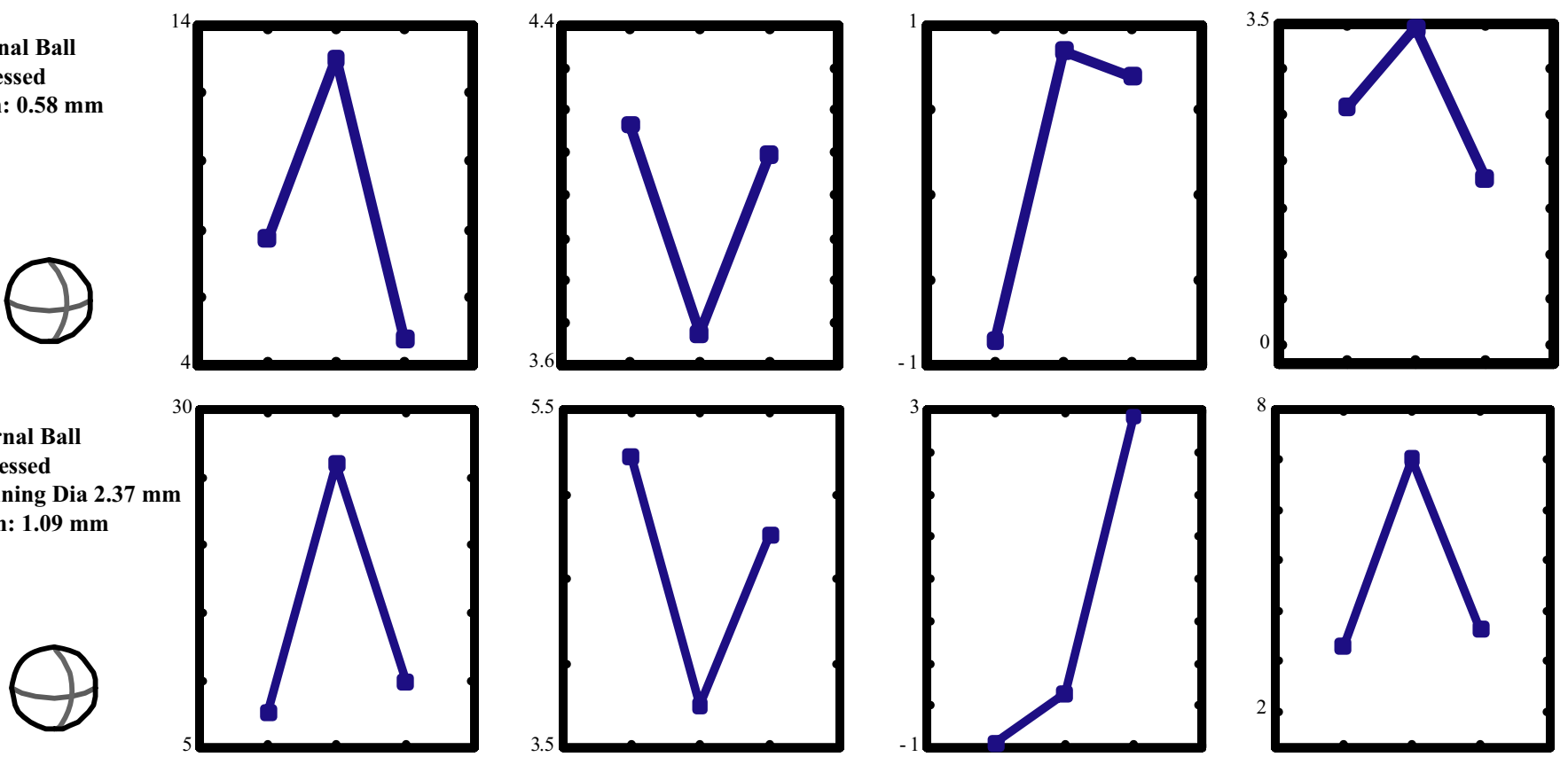

External Ball Impressed

Openning Dia $2.1 \mathrm{~mm}$ Depth: 0.65 mm

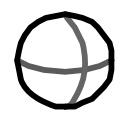

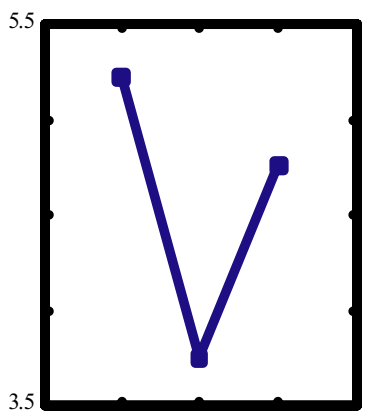
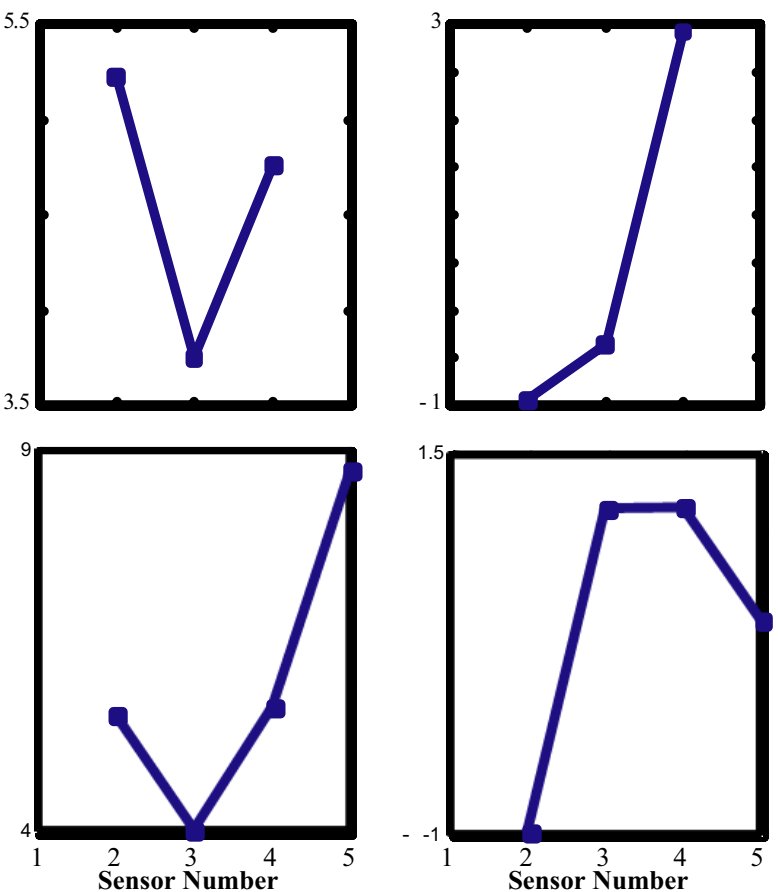
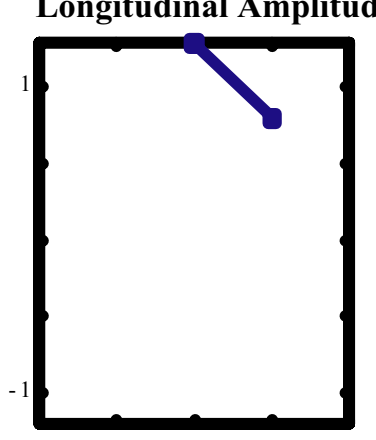
Radial Amplitude

External EDM Ball Cutter Dia 2.38 mm Depth: $1.20 \mathrm{~mm}$
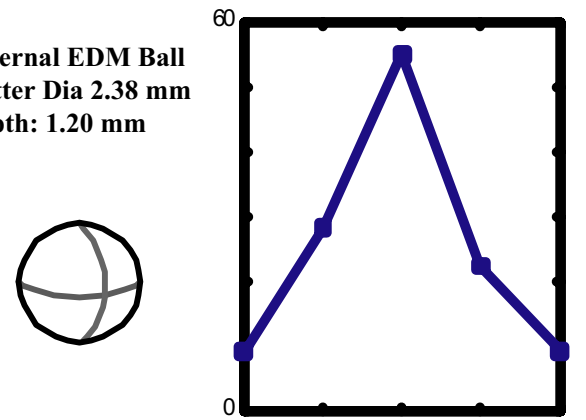

Internal EDM Ball Cutter Dia 2.38 mm Depth: 1.19 mm

$$
i_{12}^{-11}
$$

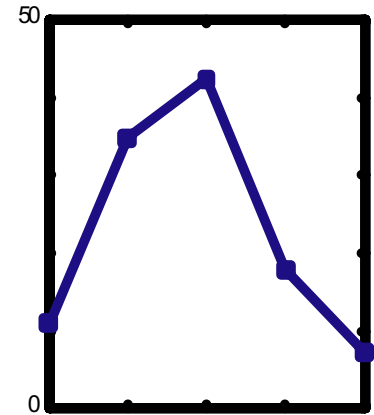

Internal EDM Bal Cutter Dia 2.05 mm Depth: $0.61 \mathrm{~mm}$

$$
\int_{1}^{\pi}
$$
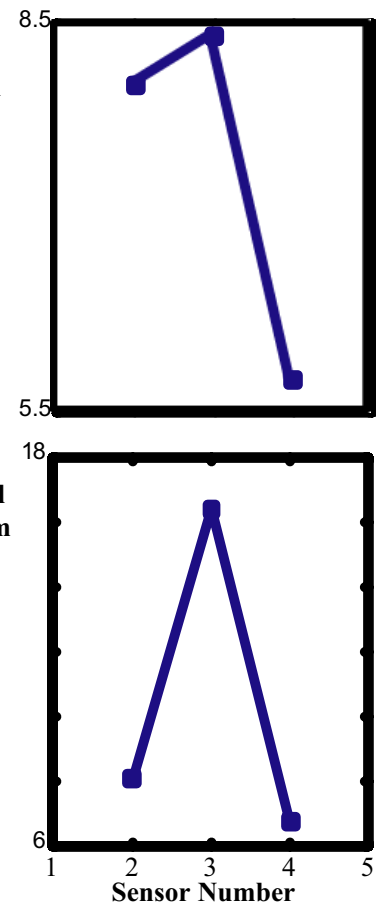

External EDM Ball Cutter Dia 2.05 mm Depth: $0.62 \mathrm{~mm}$

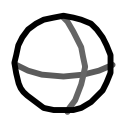

Duration of Radial Signal
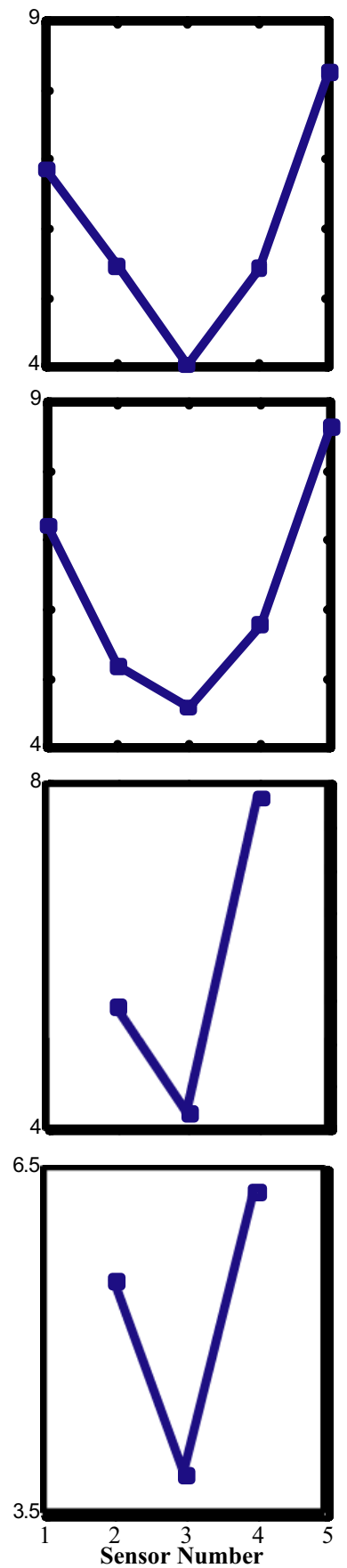

Circumferential Indicator Longitudinal Amplitude
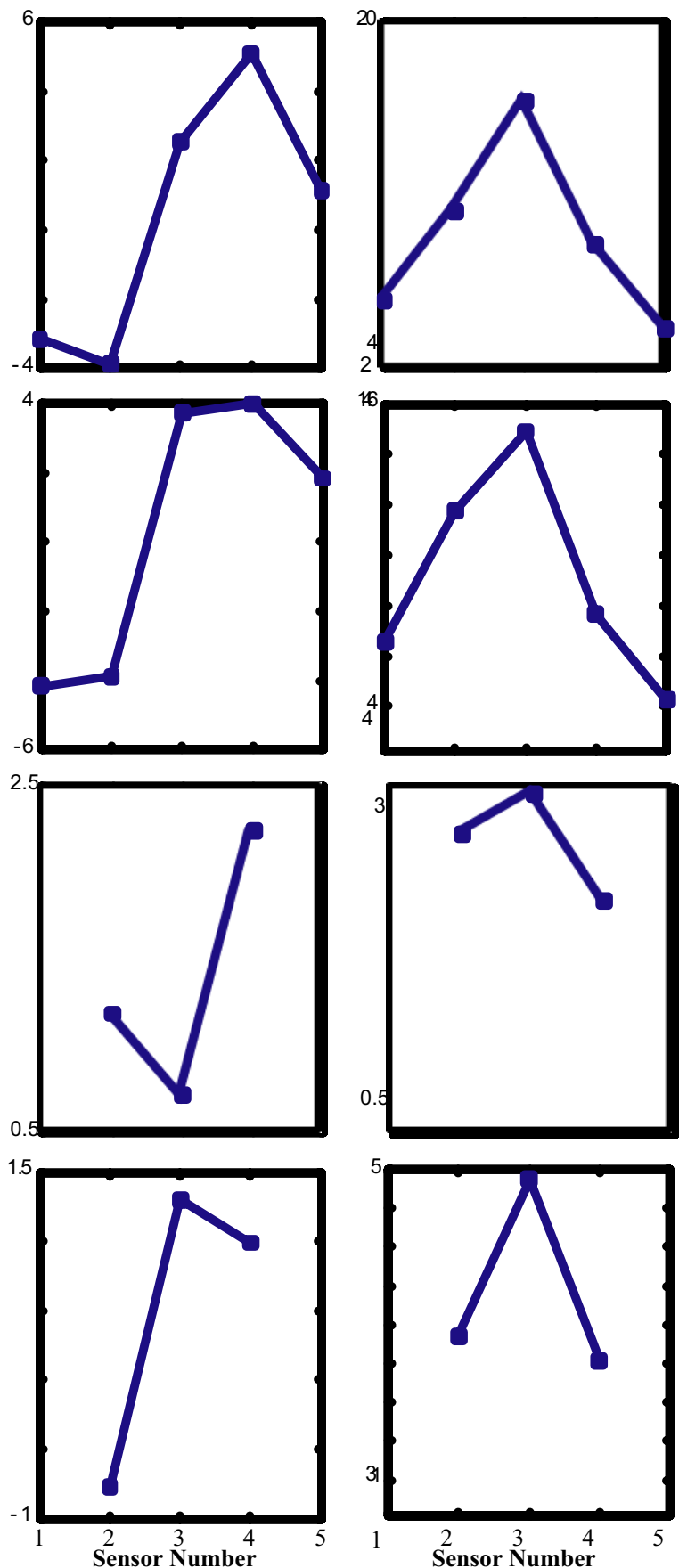
Radial Amplitude

External EDM Flat Cutter Dia $2.38 \mathrm{~mm}$

Depth: $1.30 \mathrm{~mm}$
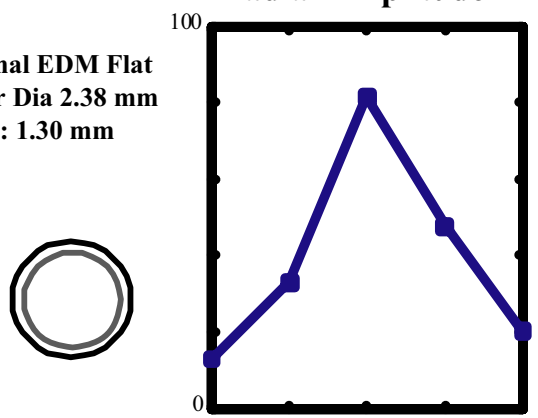

Internal EDM Flat Cutter Dia 2.38 mm Depth: $1.30 \mathrm{~mm}$<smiles>c1ccccccccc1</smiles>

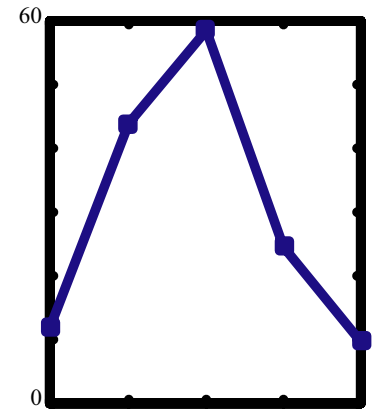

Internal EDM Flat Cutter Dia $2.38 \mathrm{~mm}$ Depth: $0.58 \mathrm{~mm}$<smiles>c1ccccccccc1</smiles>

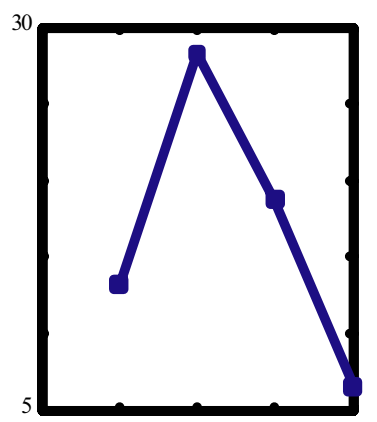

External EDM Flat Cutter Dia 2.38 mm Depth: $0.58 \mathrm{~mm}$

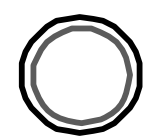

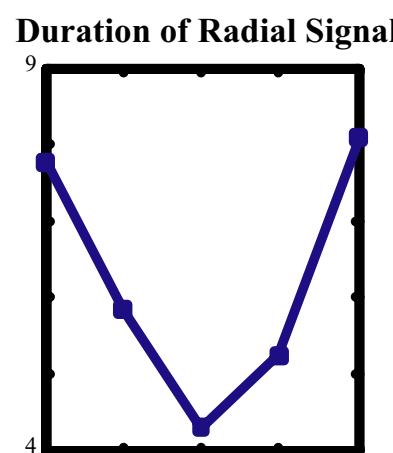

Circumferential Indicator

Longitudinal Amplitude
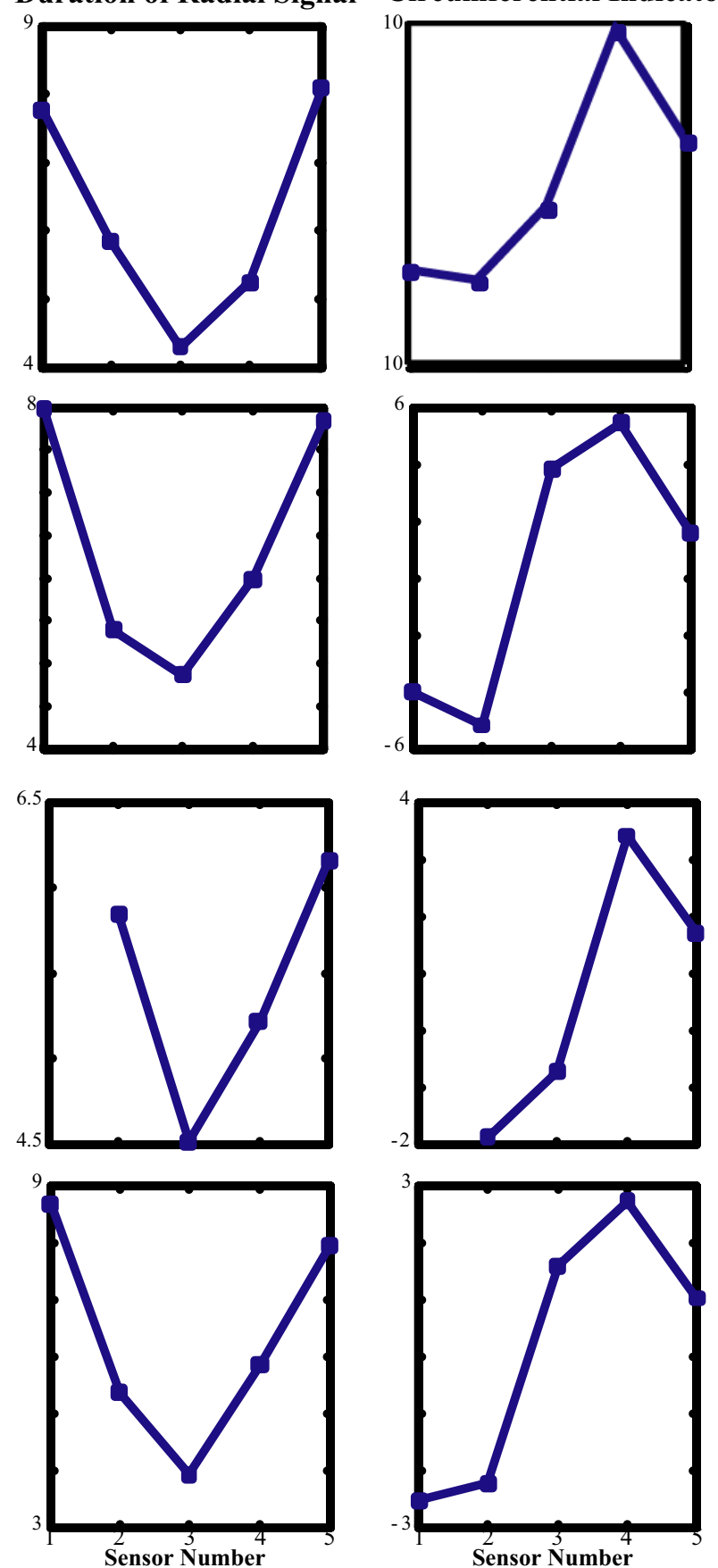
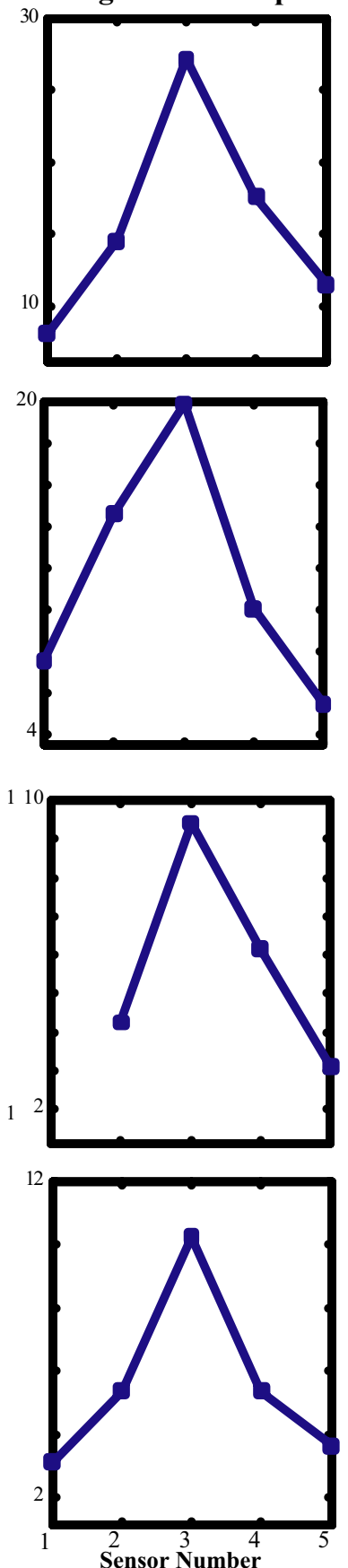
Radial Amplitude
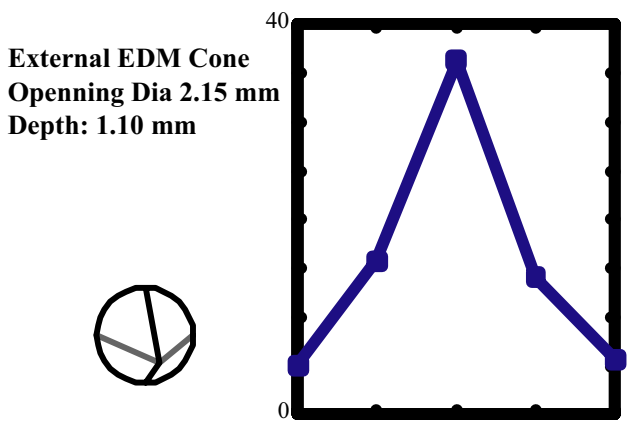

External EDM Cone Openning Dia $1.96 \mathrm{~mm}$ Depth: $0.98 \mathrm{~mm}$

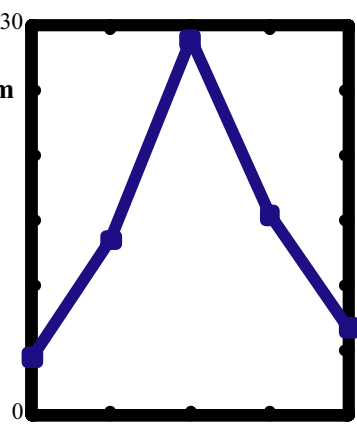

External EDM Cone Openning Dia $0.95 \mathrm{~mm}$ Depth: $0.47 \mathrm{~mm}$

$r_{1}$

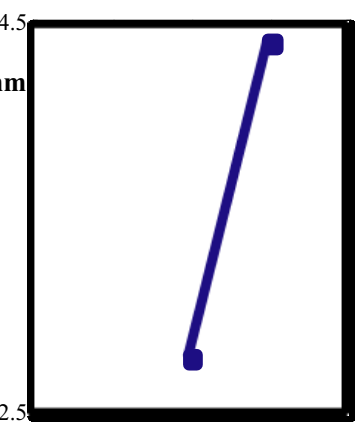

External EDM Cone

Openning Dia $1.31 \mathrm{~mm}$

Depth: $0.66 \mathrm{~mm}$

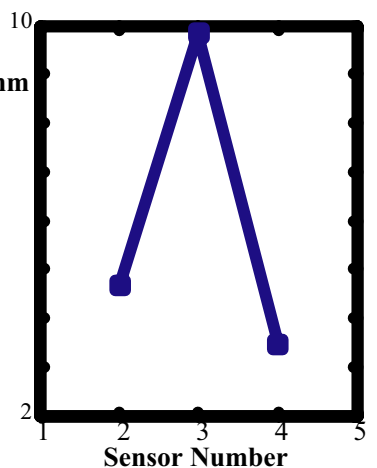

Duration of Radial Signal
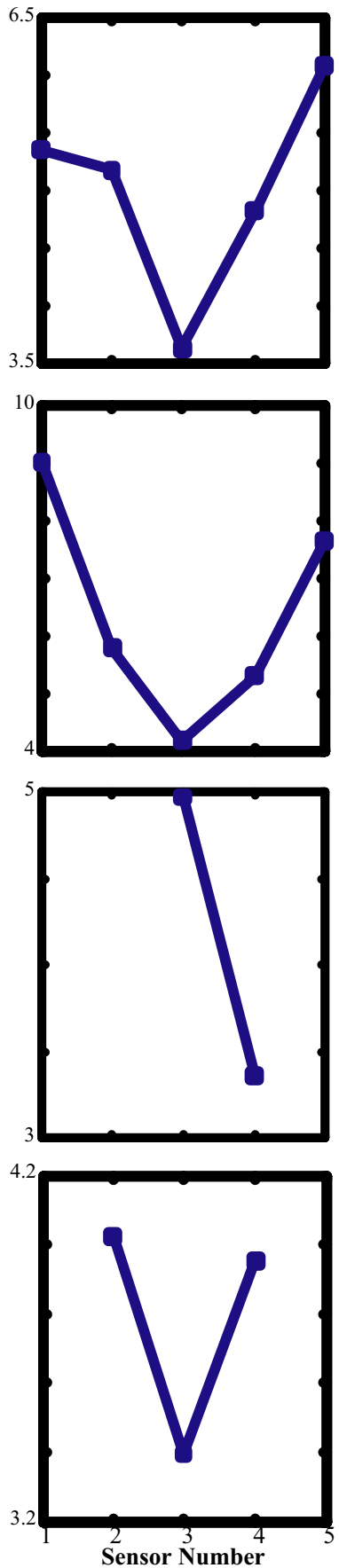

Circumferential Indicator Longitudinal Amplitude
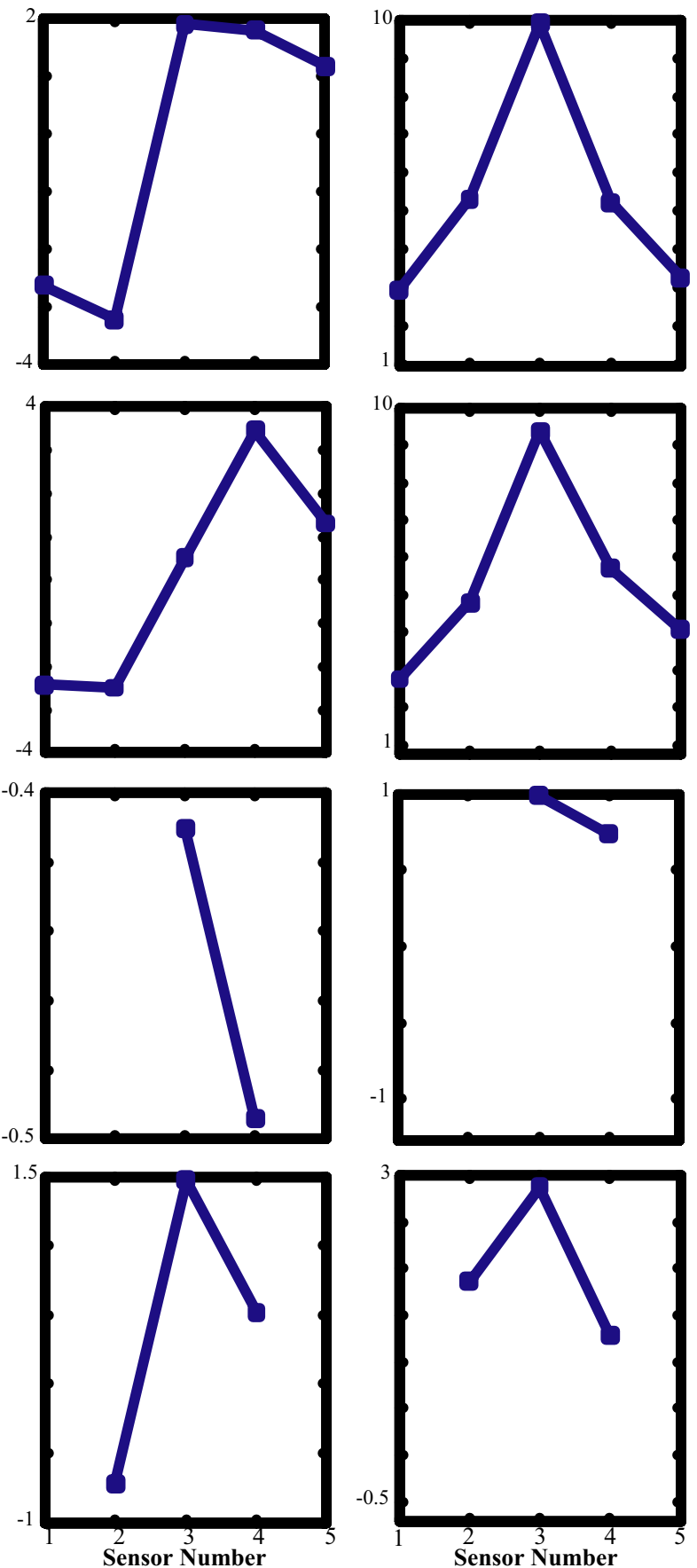
Radial Amplitude

External EDM Ball Cutter Dia $2.38 \mathrm{~mm}$

Depth: $1.21 \mathrm{~mm}$

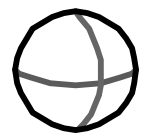

Internal EDM Ball Cutter Dia 2.38 mm Depth: $1.21 \mathrm{~mm}$

$$
i^{2}-1
$$
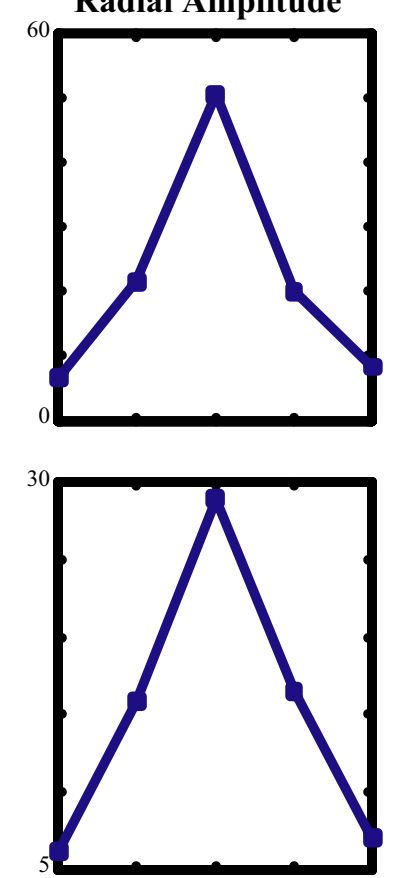

Internal EDM Ball Cutter Dia 2.02 mm Depth: 0.58 mm

$$
\int_{1}^{\infty}
$$

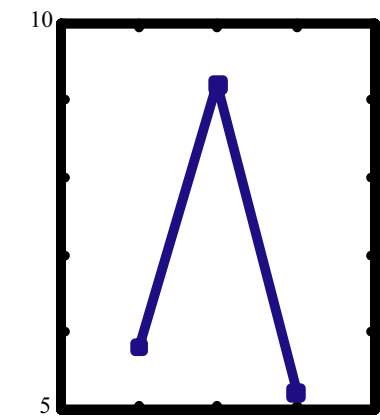

External EDM Ball Cutter Dia 2.02 mm Depth: 0.58 mm

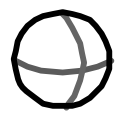

Duration of Radial Signal
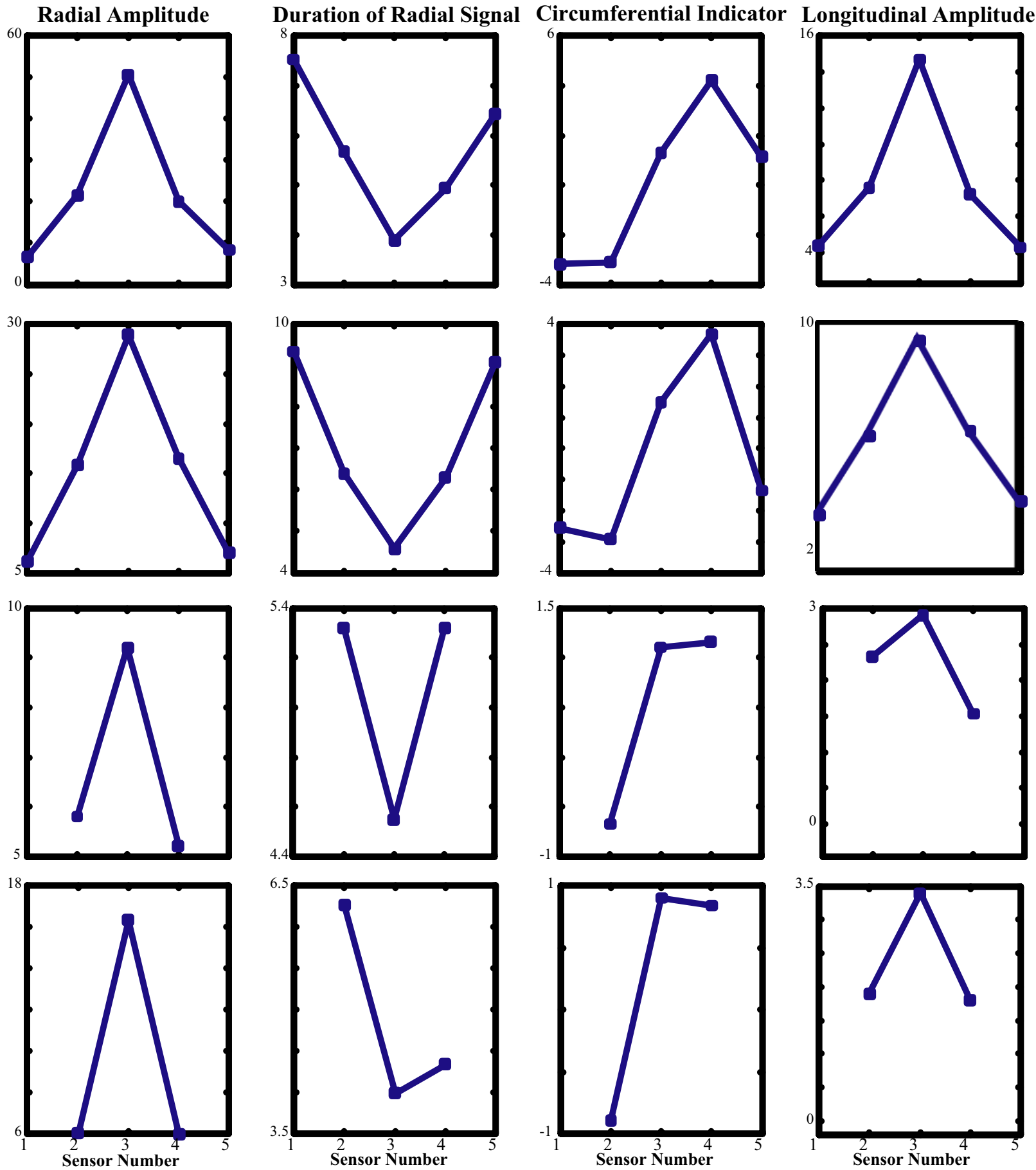
Radial Amplitude

External EDM Flat

Cutter Dia $2.38 \mathrm{~mm}$

Depth: $1.33 \mathrm{~mm}$

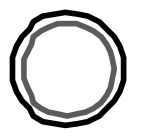

Internal EDM Flat

Cutter Dia 2.38 mm

Depth: $1.13 \mathrm{~mm}$

$$
\sum_{-2}^{\infty}
$$

Internal EDM Flat Cutter Dia 2.38 mm

Depth: $0.75 \mathrm{~mm}$

$$
i_{-2}^{\infty}
$$

External EDM Flat Cutter Dia 2.38 mm Depth: 0.73 mm

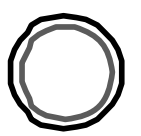

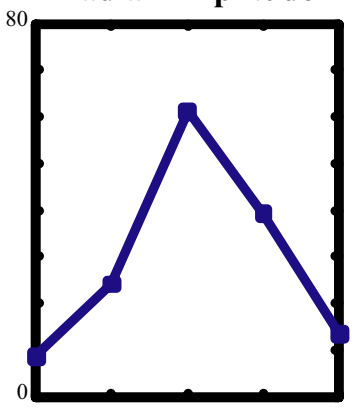
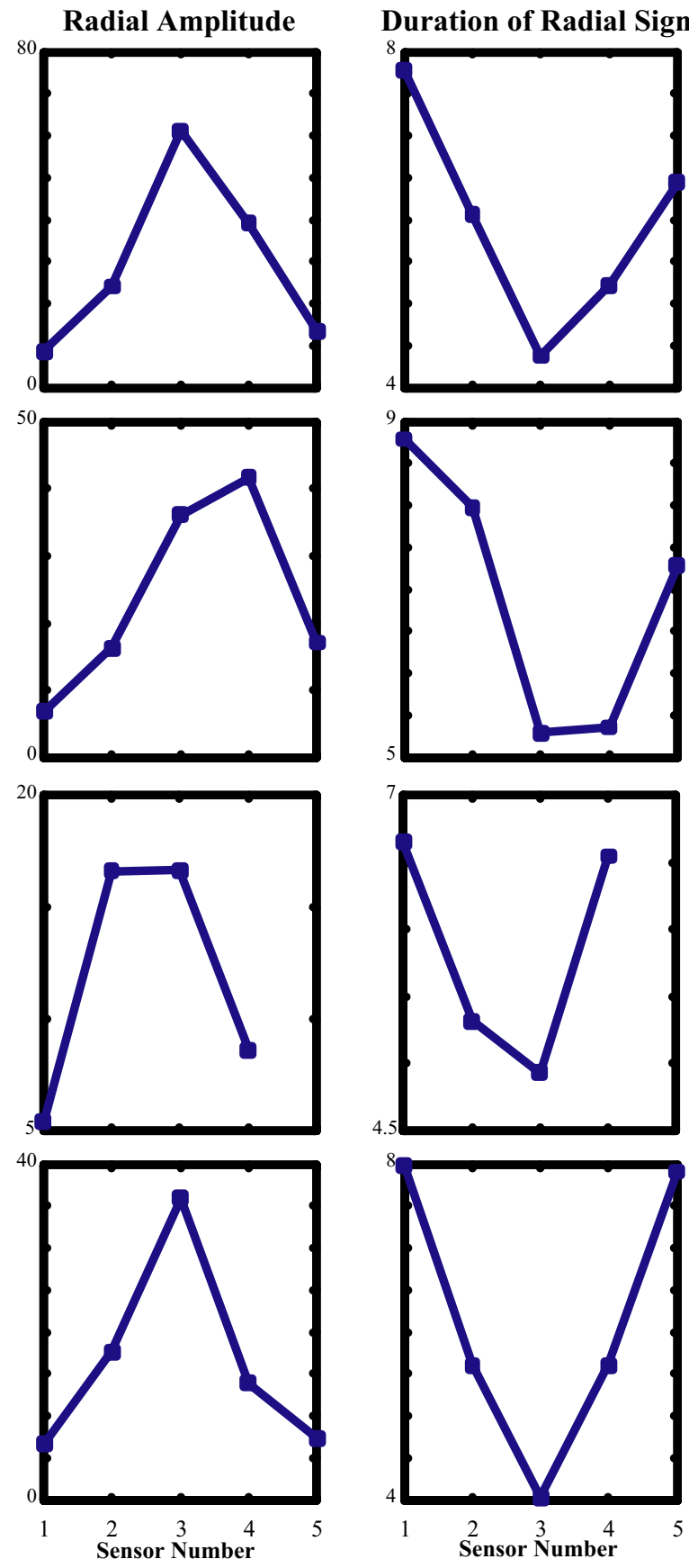
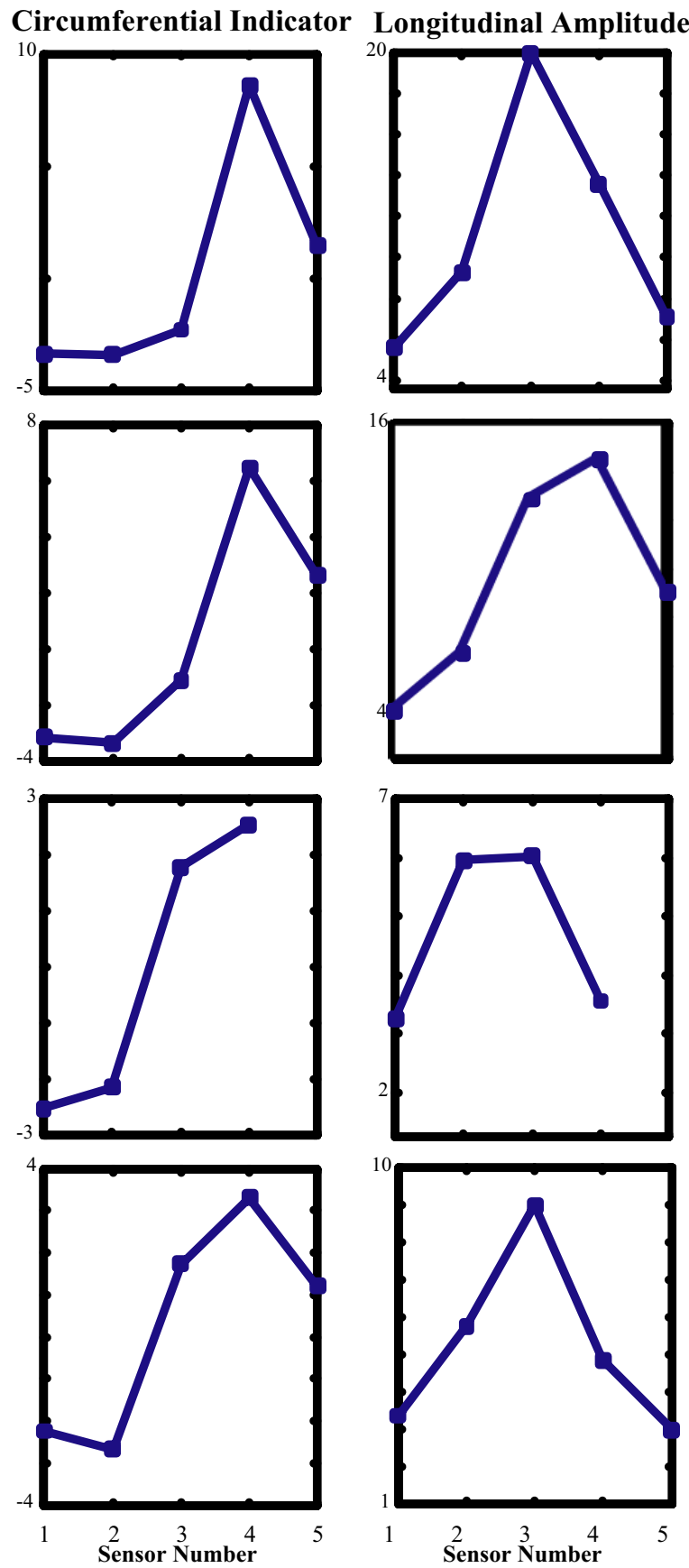
Radial Amplitude

External EDM Cone Openning Dia $2.38 \mathrm{~mm}$ Depth: $1.23 \mathrm{~mm}$
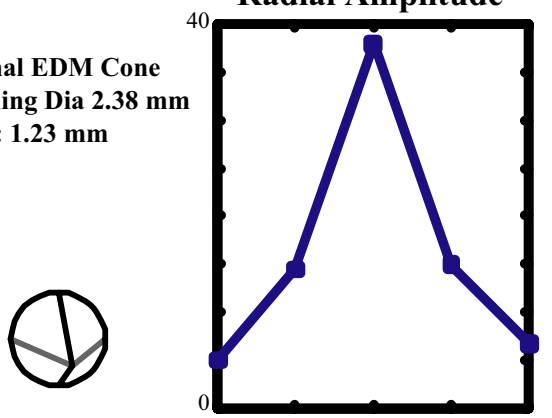

External EDM Cone Openning Dia $2.38 \mathrm{~mm}$ Depth: $1.23 \mathrm{~mm}$
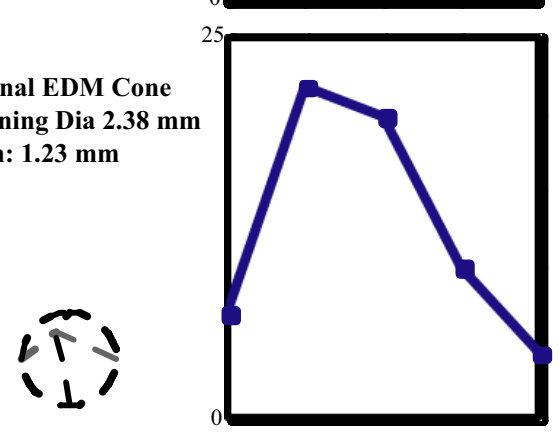

External EDM Cone Openning Dia $1.2 \mathrm{~mm}$ Depth: $0.61 \mathrm{~mm}$
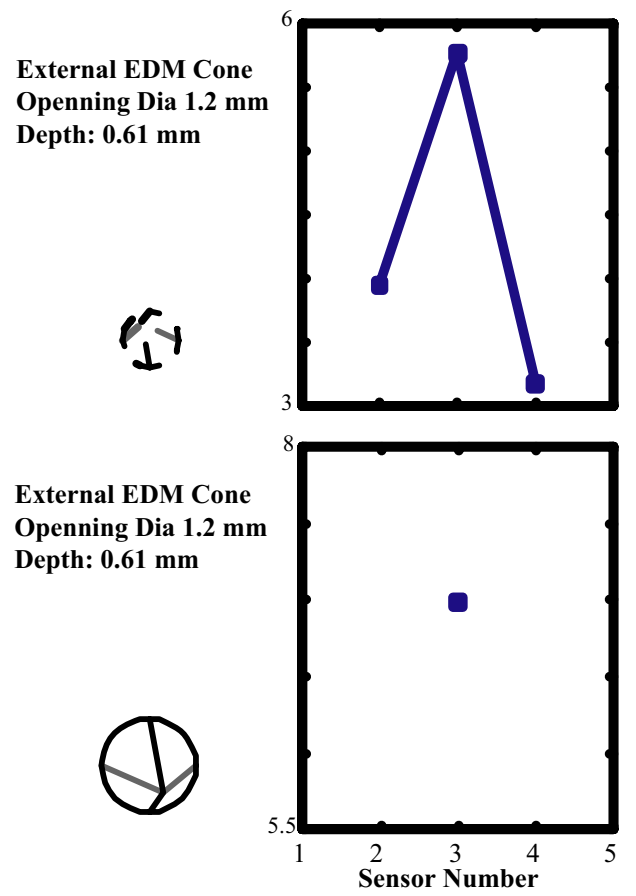

Duration of Radial Signal
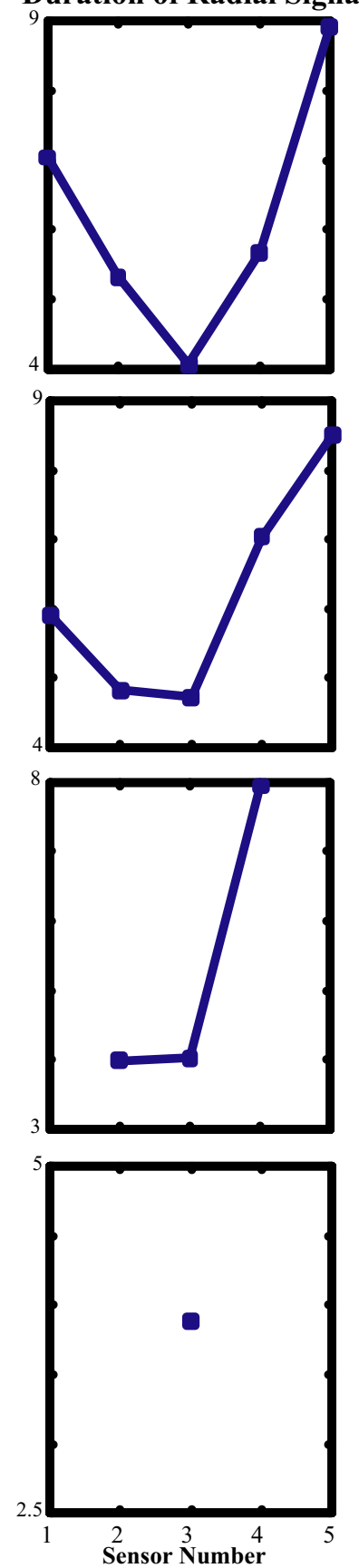

Circumferential Indicator Longitudinal Amplitude
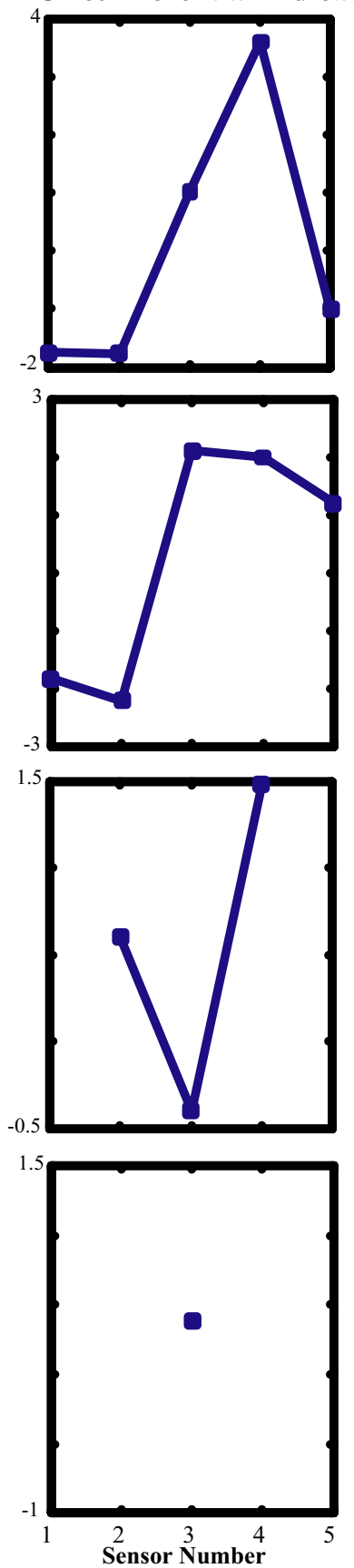
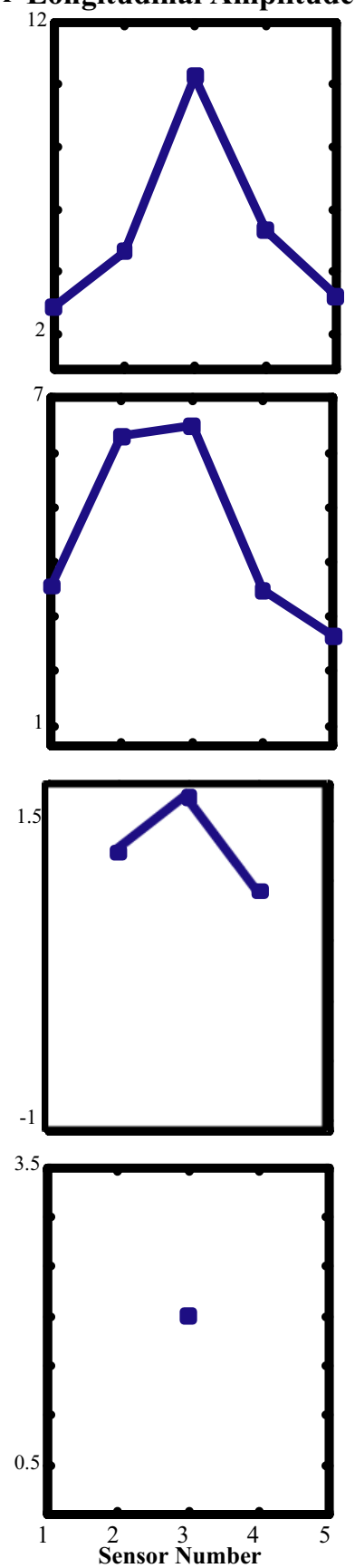